\title{
RETHINKING DETROIT
}

Raymond Owens III

Esteban Rossi-Hansberg

Pierre-Daniel Sarte

Working Paper 23146

http://www.nber.org/papers/w23146

\author{
NATIONAL BUREAU OF ECONOMIC RESEARCH \\ 1050 Massachusetts Avenue \\ Cambridge, MA 02138 \\ February 2017
}

The views expressed herein are those of the authors and do not necessarily represent the views of the Federal Reserve Bank of Richmond or the Federal Reserve System. We thank Daniel Schwam and Daniel Ober-Reynolds for outstanding research assistance and seminar participants for useful comments. The views expressed herein are those of the authors and do not necessarily reflect the views of the National Bureau of Economic Research.

At least one co-author has disclosed a financial relationship of potential relevance for this research. Further information is available online at http://www.nber.org/papers/w23146.ack

NBER working papers are circulated for discussion and comment purposes. They have not been peer-reviewed or been subject to the review by the NBER Board of Directors that accompanies official NBER publications.

(C) 2017 by Raymond Owens III, Esteban Rossi-Hansberg, and Pierre-Daniel Sarte. All rights reserved. Short sections of text, not to exceed two paragraphs, may be quoted without explicit permission provided that full credit, including ()$^{\text {notice, }}$ is given to the source. 
Rethinking Detroit

Raymond Owens III, Esteban Rossi-Hansberg, and Pierre-Daniel Sarte

NBER Working Paper No. 23146

February 2017

JEL No. F0,H0,R0

\begin{abstract}
$\underline{\text { ABSTRACT }}$
We study the urban structure of the City of Detroit. Following several decades of decline, the city's current urban structure is clearly not optimal for its size, with a business district immediately surrounded by a ring of largely vacant neighborhoods. We propose a model with residential externalities that features multiple equilibria at the neighborhood level. In particular, developing a residential area requires the coordination of developers and residents, without which it may remain vacant even if its fundamentals are sound. We embed this mechanism in a quantitative spatial economics model and use it to rationalize current city allocations. We then use the model to examine existing strategic visions to revitalize Detroit. We also explore alternative plans that rely on development guarantees, and find that they could result in greater population growth and land price appreciation than existing plans. The widespread effects of these policies underscore the importance of using a general equilibrium framework to evaluate policy proposals.

Raymond Owens III

Research Department.

Federal Reserve Bank of Richmond

PO Box 27622

Richmond, VA 23261

raymond.owens@rich.frb.org

Esteban Rossi-Hansberg

Princeton University

Department of Economics

Fisher Hall

Princeton, NJ 08544-1021

and NBER

erossi@princeton.edu

Pierre-Daniel Sarte

Research Department.

Federal Reserve Bank of Richmond

PO Box 27622

Richmond, VA 23261

pierre.sarte@rich.frb.org
\end{abstract}




\title{
Rethinking Detroit*†
}

\author{
Raymond Owens III \\ Federal Reserve Bank of Richmond
}

\author{
Esteban Rossi-Hansberg \\ Princeton University
}

\author{
Pierre-Daniel Sarte \\ Federal Reserve Bank of Richmond
}

February 4, 2017

\begin{abstract}
We study the urban structure of the City of Detroit. Following several decades of decline, the city's current urban structure is clearly not optimal for its size, with a business district immediately surrounded by a ring of largely vacant neighborhoods. We propose a model with residential externalities that features multiple equilibria at the neighborhood level. In particular, developing a residential area requires the coordination of developers and residents, without which it may remain vacant even if its fundamentals are sound. We embed this mechanism in a quantitative spatial economics model and use it to rationalize current city allocations. We then use the model to examine existing strategic visions to revitalize Detroit. We also explore alternative plans that rely on development guarantees, and find that they could result in greater population growth and land price appreciation than existing plans. The widespread effects of these policies underscore the importance of using a general equilibrium framework to evaluate policy proposals.
\end{abstract}

\section{Introduction}

The City of Detroit, an iconic example of urban development associated with modern industrialization, is in disarray. Large declines in population over several decades have resulted in a city structure that is clearly inefficient and that severely inhibits economic outcomes in the city. A business area that contains the headquarters of large automobile companies such as General Motors, Ford and Chrysler and that employs hundreds of thousands of people, is surrounded by nearly deserted residential areas that have been mostly

\footnotetext{
*Owens: raymond.owens@rich.frb.org. Rossi-Hansberg: erossi@princeton.edu. Sarte: pierre.sarte@rich.frb.org.

${ }^{\dagger}$ The views expressed herein are those of the authors and do not necessarily represent the views of the Federal Reserve Bank of Richmond or the Federal Reserve System. We thank Daniel Schwam and Daniel Ober-Reynolds for outstanding research assistance and seminar participants for useful comments.
} 
abandoned or demolished. This structure violates the most basic economic principles of urban design where residents utilize areas close to their employers to minimize commuting costs. The incentives to revitalize these vacant areas around Detroit's central business district are not generating the needed investments and changes in the city. In this paper, we propose a quantitative economic model of the city of Detroit that can help us rationalize the current state of the city and evaluate a variety of plans and policies that have been proposed to improve its structure.

The problems of Detroit are not unique. Many cities throughout the industrialized world have experienced similar problems. The decline in manufacturing employment, and the displacement of manufacturing from urban centers, have resulted in the decline of many cities for long periods of time. As Glaeser and Gyourko (2005) argue, these declines can be protracted owing to the durability of the housing stock. Negative shocks to the industries operating in a city, or to the regional economy, lead to immediate declines in land rents but also to protracted declines in population that follow the slow depreciation of buildings and structures. However, while Detroit has demolished well over one hundred thousand housing units since the 1980's, the city has not experienced any substantial adjustment in its basic layout or structure. Thus, the slow depreciation of housing initially built before the 1930's cannot be the main culprit of its evolution. This lack of adjustment has arguably led to an under-utilization of its urban infrastructure. The system of streets and highways built for a city three times its current size is not serving new booming industries but, as in many other rustbelt cities, is weighing on its recovery. In particular, the high cost of maintaining this large infrastructure has led to fiscal problems, an under-provision of essential public services, and ultimately to bankruptcy and default (Detroit filed for chapter 9 bankruptcy in 2013).

Sectoral and local shocks that have led to these salient changes in urban landscape are not exceptional. As new production technologies and trading possibilities lead to declines in today's booming industries, changing the comparative advantage of countries and regions, similar secular changes are to be expected in the future. Moreover, environmental changes such as climate change and coastal flooding are likely going to change the productivity and residential amenities of today's cities. Dealing effectively with declining cities then is an important challenge that requires careful policy design and measurement. Developing the appropriate policies to improve the structure of declining cities can generate not only gains for its residents, but could also lead to a better, and more efficient, use of resources and spatial allocation of economic activity in the U.S., and the world.

A stylized look at the structure of the city of Detroit reveals a surprising pattern: a downtown area with healthy numbers of employees and employers surrounded by a ring of vacant neighborhoods. Most of these neighborhoods have been abandoned or demolished over the years, and in some of these areas, the city has stopped providing services. The main question that arises when confronted with this structure, vividly captured in Figure 1, is: why do residential developers not move into these areas and develop residential communities where downtown workers can live?

With residential areas close to downtown, workers would clearly save on commuting and downtown Detroit would benefit from more foot-traffic and demand for retail and other services. The basis of our 


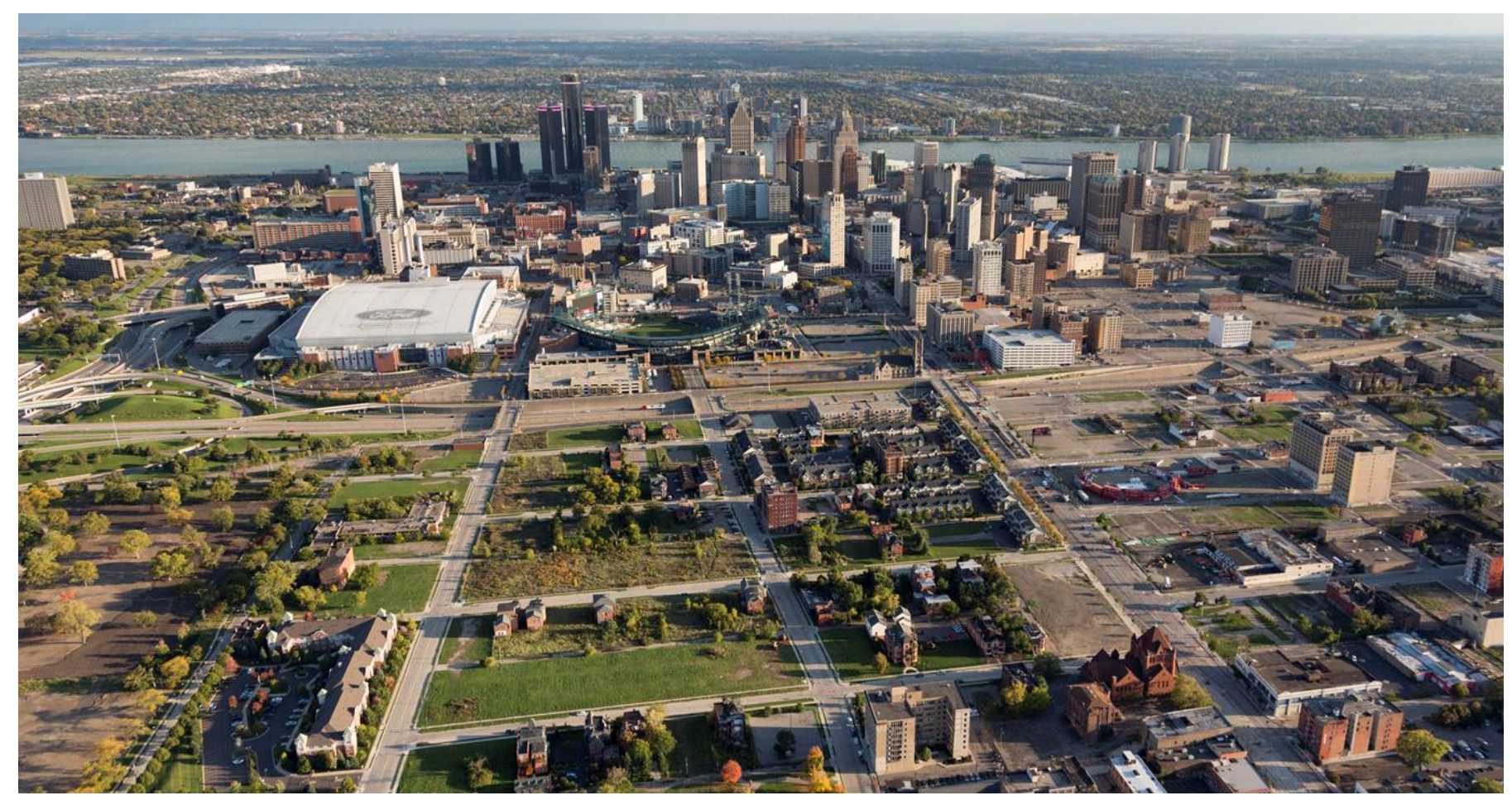

Figure 1: The neighborhood of Brush Park in the foreground, downtown Detroit in the background, as capured by the New York Times, Oct. 14, 2014

argument is simple and intuitive: residents do not want to be isolated in a neighborhood. They desire other residents with whom to socialize and who require the services they wish to consume. Neighborhood development then requires a large enough scale because of residential and housing externalities (as in RossiHansberg et al., 2010), one that individual residential developers are not able, or not willing, to provide on their own. Hence, neighborhoods have two equilibria, one that features a residential area with enough development and residents to make it sustainable, and one in which no investment is made and no residential activity occurs.

The issue of coordination among developers, and between developers, residents, and local governments, is explicitly recognized as a key challenge in previous studies of Detroit's ailments. Among the most comprehensive of those studies is a set of reports and proposals provided by Detroit Future City (DFC), a civic organization created in 2012 that includes planning experts, community leaders, and residents, and whose mission is to guide and help implement the revitalization of Detroit. The DFC reports repeatedly cite references to challenges in coordinating different parties as a key impediment to revitalization and development 1

\footnotetext{
${ }^{1}$ In particular, the DFC Strategic Framework (2012) stresses that "Detroit's ability to address its problem property issues is impeded by its severe fiscal and market constraints, but it is equally impeded by the absence of a systematic, coordinated approach to the problem, in which all public and private stakeholders are fully engaged."
} 
Thus, we place this coordination problem at the center of our analysis and embed it in a quantitative spatial economics framework that allows us to model the city of Detroit in detail. We then use the model to design and quantify the effects of a variety of policy proposals, including different strategic visions proposed, but not quantified, by DFC. The general equilibrium framework we develop for Detroit is close to the literature on quantitative spatial economics recently reviewed in Redding and Rossi-Hansberg (2016). The key addition to this literature, aside from a careful quantification of an urban model for the city of Detroit, is the existence of residential externalities that lead to the coordination problem and multiplicity of neighborhood equilibria described above. This novel mechanism allows us to both rationalize current allocations in the city of Detroit and quantify the effects of various policy proposals.

The policies that we assess all involve coordinating on vacant residential neighborhoods. In particular, we consider 'development guarantees' to resolve coordination challenges where the city government, or some other outside institution, guarantees a minimum investment in residential development in a neighborhood targeted for development. We then use our quantitative framework to compute the magnitude of the required guarantees that would allow a neighborhood to coordinate in the equilibrium with a positive number of residents and residential investment. If the policy is successful, the guarantee is never called upon and the policy is costless. We compute the overall effect of policies addressing different areas of Detroit on a variety of outcomes in the treated and non-treated neighborhoods. In our analysis, these outcomes reflect in part all general equilibrium linkages embedded in the spatial structure of Detroit. We show that carrying out the analysis in a general equilibrium framework, where locations are linked by commuting, is essential for the generated outcomes. We further use our quantitative set-up to design policies that maximize the net gains for Detroit, and compare their effects with those stemming from various proposals that DFC has advocated, but not quantified, as possible equilibria. Our newly designed policies can yield gains of hundreds of millions of dollars in additional land rents per year, and perform substantially better than the DFC proposals.

We carry out our analysis at the census tract level, which is the smallest unit for which commuting data can be accurately matched to other aspects of Detroit such as workplace wages, employment, residential prices and land use ${ }^{2}$ We collect data from a variety of sources that include bilateral census commuting data, local development and price data from assessors, local Detroit organizations focused on measuring urban blight, and Google Analytics data on actual commuting times and distances between census tracts. The resulting dataset is quite rich and allows us to quantify the model at a high level of detail. The hope is that such a quantitative framework will inform the decision making process in Detroit and other declining cities, and transform them into cities that can host the industries of the future.

The rest of the paper is structured as follows. Section/2 provides a brief account of Detroit's recent history. Section 3 presents the model and Section 4 describes how it is given quantitative content. Section 5 discusses

\footnotetext{
${ }^{2}$ In principle, commute data is available at the block level from the Longitudinal Employer-Household Dynamics, Origin Destination Employment Statistics (LODES) data set. However, LODES indicates that uncertainties in block coding make block analyses unreliable, see Abowd, Stephens, Vilhuber, Andersson, McKinney, Roemer, and Woodcock (2005). Moreover, as pointed out in Couture and Handbury (2016), noise infusion to maintain confidentiality at the block level further encourages aggregation to the tract level for accurate analysis.
} 
the policy counterfactuals and designs of alternative policies. Section 6 concludes. Appendix A provides additional derivations not included in the text, while an on-line appendix provides a detailed description of the data used to inform our analysis, and considers a variety of additional policy counterfactuals and alternative model assumptions.

\section{City of Detroit}

To get a sense of Detroit's evolution from world famous city to hollow shell during the past hundred years, it is useful to note that the city entered the twentieth century as mid-tier American city of about 286,000 residents. Connected to the Great Lakes through its location on the Detroit River, the city had access to waterborne shipments of iron ore from Minnesota and coal and oil from areas south. Metal related production, from smelting to machinery production arose there, among other types of production.

By 1900 automobile producers were active in Detroit, though vehicle production numbered only a few hundred units per year rising to a few thousand by mid-decade. Two developments changed the city into the center of automobile production, however. The first was Ford Motor Company's design of a simple, rugged automobile, the Model T. The second was Henry Ford's adoption of the assembly line for automobile production beginning in late 1913. In combination, these developments provided a viable product for the rough roads of the U.S. and technology that lowered labor costs required to assemble the Model T, making automobiles affordable to the masses. The assembly line was rapidly employed by other automobile producers.

As demand for automobiles soared, Ford and other producers constructed factories that stretched a half mile or more, in some instances. To man the vast factories, Ford and other companies in Detroit needed far more labor than was available locally. To obtain enough workers, automobile producers raised wages to attract labor from the American south, Europe, the Middle East and other regions around the world (Sugrue, 2007; Sugrue, 2015). By 1930, automobile production at Detroit's largest companies neared a peak that would not be surpassed until after World War II.

To house the workers, residential developers constructed vast tracts of single-family homes in seemingly endless blocks stretching out on the plain surrounding the existing city. Detroit's population reached nearly a half million by 1910, almost one million by 1920 and approached 1.5 million by 1930 . Figures 2 shows that housing constructed before 1930 (in red) mainly surrounded the existing city in a broad band. Census records from 1910 and 1920 indicate that many workers living in this band worked in automobile-related manufacturing jobs (Minnesota Population Center and Ancestry.com, 2013). Subsequent census data from 1920, 1930, 1940 and 1950 show that the density of blue collar manufacturing jobs remained higher in this band than in other areas of Detroit (Bogue, 2000; Minnesota Population Center and Ancestry.com, 2013).

As of 1950, Detroit built one of every two cars produced in the world, and the city's population topped 1.8 million. But two developments during the decade laid the foundation for a prolonged period of decline for the city. The first was a decision by the automobile companies to locate production plants outside of the 
Detroit area. Both labor unrest in Detroit and the desire to locate closer to customers have been cited as reasons for diversifying plant locations. A second was the initiation of the interstate highway system, which would bring express highways through the city beginning less than a decade later (Sugrue, 1996; Sugrue, 2007; Sugrue, 2015).

As the 1960s arrived, Detroit saw population declines and job losses related to automobile production mount. Unemployed households increased rapidly in the band surrounding downtown that had been built prior to 1930 (Bogue, 2000; Minnesota Population Center, 2016). Related to the ongoing job losses and diminished economic prospects, residents of the area became increasingly on edge and racial tensions became more pronounced. Tensions exploded in the summer of 1967 with five days of rioting and looting following a police raid on an illegal club. Over 2500 stores were burned, looted or destroyed in the episode, nearly all of them businesses located within the band of housing built before 1930 .

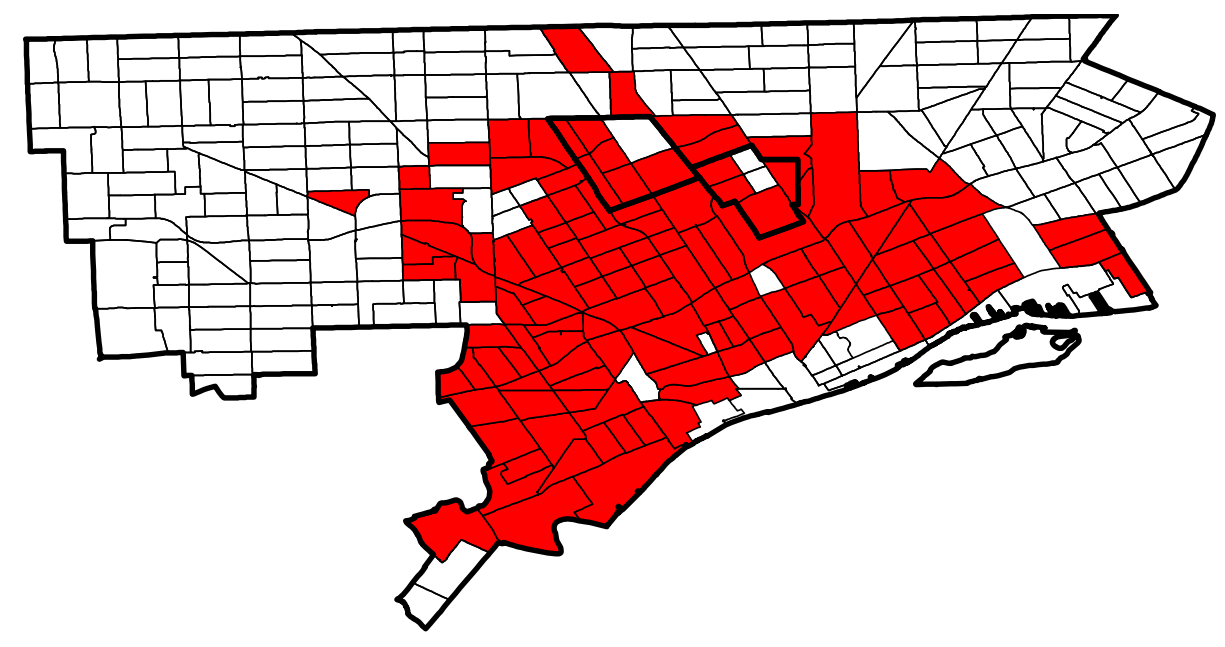

Figure 2: Pre-1930 residential census tracts in Detroit with at least 75 percent of residential properties built prior to 1930

In the riots' aftermath, existing households in the area found fewer businesses to serve them (600 grocery stores were damaged or destroyed, for example) and were concerned about safety going forward. Business owners who were not insured often could not reopen their operations. Those who were insured assessed the changed environment of the area and many were not confident that their customers-both households and other business-would remain. The prospect of fewer customers in the area led many to not reopen in the city. With the interstate highway construction well underway by 1967, some businesses and residents chose to relocate to suburbs outside of Detroit. In the end, the perception of increased danger, lower commute costs, and a lack of coordination between residents' location plans and those of neighborhood businesses, contributed to an acceleration of the outflow of businesses and residents. Home values fell and new residents entering the area had lower incomes on average. 


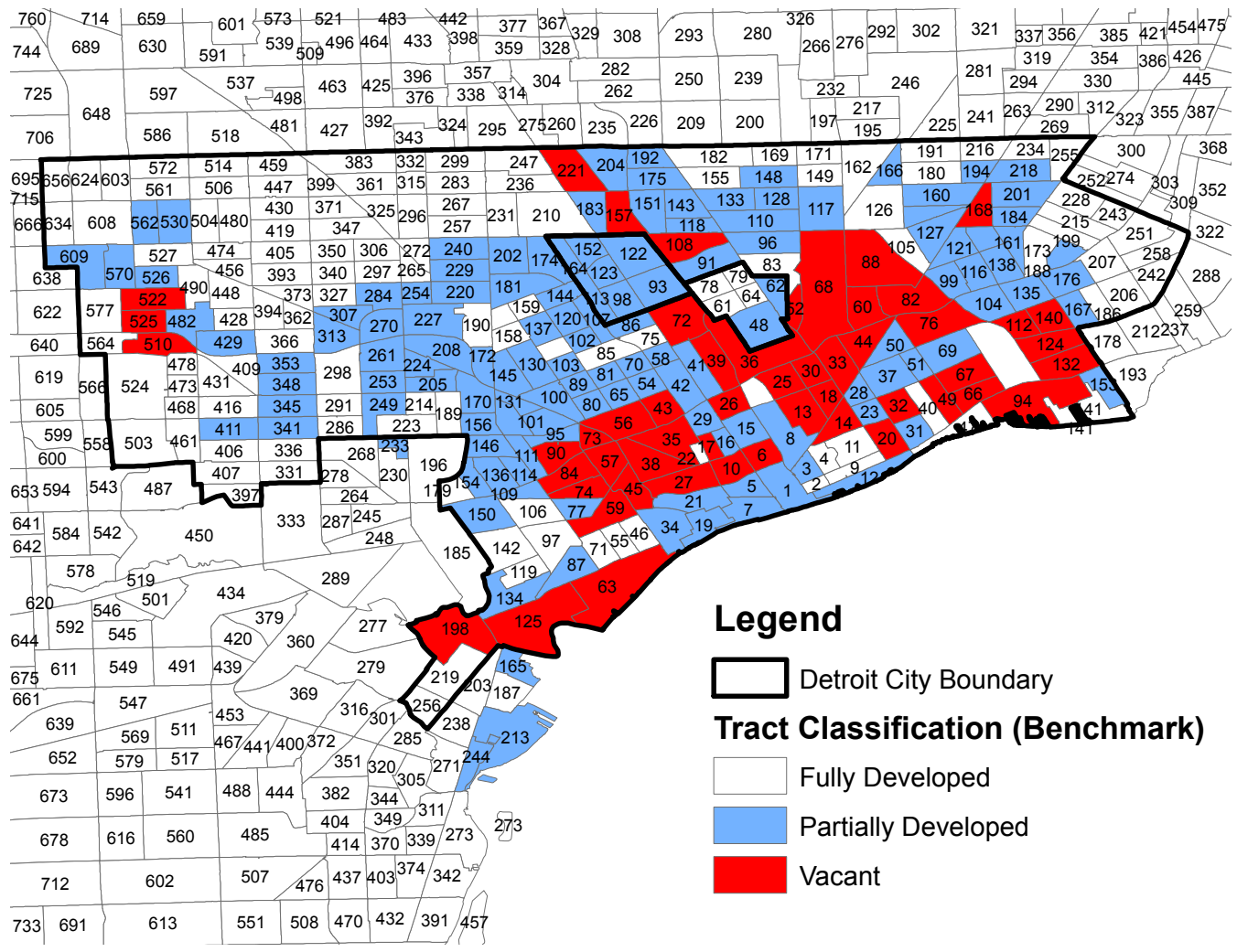

Figure 3: Empty and Partially Developed Census Tracts in Detroit Today

In the decades following the riots, Detroit's landscape continued to show the scars of the riots. Vacant lots where businesses were not rebuilt were eventually joined by vacant lots where houses once stood. The spreading vacancies resulted from a cycle in which lower wages and high unemployment in the band of the city led to the inability, or unwillingness, of lower income residents to maintain some homes, lowering home values and the corresponding city tax revenues. The reductions in tax revenues were not matched by lower costs of providing city services to increasingly sparsely populated areas of Detroit, however (Scorsone, 2013).

Over time, houses were abandoned as the value of the housing services at locations in the pre-1930 band fell further. Crime rates rose and tax revenues declined to the point that the city curtailed services to some areas of the city. Under Mayor Dave Bing, proposals to bulldoze tens of thousands of abandoned homes began in an effort to reduce crime occurring in and around the vacant structures. Proposals from the mayor also suggested clearing sparsely populated areas and relocating remaining residents to more densely populated areas to concentrate the provision of city services to "viable" areas of the city (Bing, 2010). But the relocations did not occur, and many blocks adjacent to downtown Detroit were dominated by empty lots and high vacancy rates of the remaining housing stock. House prices fell to essentially zero in some of these areas. As a result, the nation's once fourth largest city became the poster child for urban decay. 
The resulting city structure is presented in Figure 3. The figure classifies the census tracts in Detroit and surrounding areas as featuring full residential development, partial residential development, or no residential development (vacant) ${ }^{3}$ It also features the number code for the census tract and the boundary of Detroit proper. The census tracts that are labeled vacant largely correspond to the neighborhoods constructed before 1930 (see Figures 2 and 3), and form a rough half-ring outside the central business district.

\section{The Model}

We now describe a spatial framework that will allow us to describe the current state of Detroit quantitatively along various dimensions such as employment, residential population, commuting, and land prices. With this quantitative framework in hand, we will then be in a position to carry out various counterfactual exercises aimed at assessing the effectiveness of different policy proposals.

Consider a city that consists of a set of $J$ areas located on a two dimensional surface, indexed by $j$ (or $i$. Space in these locations can be used for either residential or business purposes, and the amount of space designated for each use is determined by law according to the city zoning ordinance. We denote by $\bar{T}_{j}^{b} \geq 0$ the total area zoned for business land and $\bar{T}_{j}^{r}$ the total area of land zoned for residential purposes at location $j$. Actual developed residential land, $T_{j}^{r}$, is determined in equilibrium, but $T_{j}^{r} \leq \bar{T}_{j}^{r}$. In the model, business land is always developed so $T_{j}^{b}=\bar{T}_{j}^{b}$. Three types of agents live and do business in the city, namely residents, firms, and residential developers. Individuals can move freely in and out of the city and can obtain a utility $\bar{u}$ elsewhere in the economy. If they choose to live in the city, they also decide where to live and work, and how much consumption and housing services to acquire. Firms produce a single consumption good and choose where and how much to produce of that good. Residential developers decide where to build housing units that individuals rent to live.

\section{1 $\quad$ Firms}

Firms produce the single consumption good using land and labor and a constant returns to scale technology. Productivity in a location $j$ is determined by a local component, $A_{j}$, that determines how suitable the location is for goods production, and an agglomeration component determined by the density of employment in the area. This second component constitutes an externality that producers take as given. In particular, if $L_{j}$ denotes the total number of workers in location $j$, then $l_{j} \equiv L_{j} / T_{j}^{b}$ denotes workers per unit of business land in the area, and productivity is given by $a\left(l_{j} ; j\right)=A_{j} l_{j}^{\alpha}$ for $\alpha>0$.

Production per unit of land in the business district of location $j$ is then given by

$$
\frac{Y_{j}}{T_{j}^{b}} \equiv y_{j}=a\left(\frac{L_{j}}{T_{j}^{b}} ; j\right)\left(\frac{L_{j}}{T_{j}^{b}}\right)^{\beta} \equiv\left(A_{j} l_{j}^{\alpha}\right) l_{j}^{\beta} .
$$

\footnotetext{
${ }^{3}$ The methodology underlying this classification is explained in Section 4 below.
} 
Let $w_{j}$ denote the wage in location $j$. Then, the problem of firm $k$ is given by

$$
\max _{l_{k j}} a\left(l_{j} ; j\right) l_{k j}^{\beta}-w_{j} l_{k j}
$$

where $l_{k j}$ denotes firm $k$ 's choice of workers per unit of land. We assume that firms are small and so do not internalize the local externality. Hence, firms do not take into account the dependence of productivity on equilibrium density, $l_{j}$. The representative firm's first order condition is given by

$$
\beta a\left(l_{j} ; j\right) l_{k j}^{\beta-1}=w_{j}
$$

Since all producers at $j$ are identical, in equilibrium $l_{k j}=l_{j}$ for all $k$. Hence, using $a\left(l_{j} ; j\right)=A_{j} l_{j}^{\alpha}$,

$$
l_{j}=\left(\frac{A_{j} \beta}{w_{j}}\right)^{\frac{1}{1-\beta-\alpha}}
$$

so that local labor demand at $j$ is given by

$$
L_{j}=\left(\frac{A_{j} \beta}{w_{j}}\right)^{\frac{1}{1-\beta-\alpha}} T_{j}^{b} .
$$

Throughout the paper, we assume that $1-\beta>\alpha$ to guarantee that local labor demand is downward sloping. Namely, the congestion force, governed by the share of land in production, $(1-\beta)$, that determines the decreasing returns to labor, is stronger than the agglomeration force, determined by the elasticity of productivity with respect to employment density, $\alpha$.

Firms compete for land and are willing to bid for business land at $j$ until they make zero profits. Hence, the commercial rent at $j$ is

$$
q_{j}^{b}=(1-\beta) A_{j}^{\frac{1}{1-\beta-\alpha}}\left(\frac{\beta}{w_{j}}\right)^{\frac{\beta+\alpha}{1-\beta-\alpha}} .
$$

We assume that business land is owned by absentee landlords.

\subsection{Individuals}

Agents consume goods and housing at their residential location and commute to a business area where they receive a wage. Agents experience their place of residence differently depending on local residential amenities. Amenities depend on the characteristics of the neighborhood, for example its beauty or convenience, as well as on the number of other residents living in the area, $R_{j}$. In addition, agents are allowed to have idiosyncratic preferences for particular residence-work combinations as in Monte et al. (2016).

The preferences of an individual living in location $j$ (with $R_{j}$ residents) and working in $i$, who consumes

$C_{i j}$ goods, lives in a house that provides housing services given by $H_{i j}$, and has idiosyncratic preference for 
the residence-work pair $i j$ parametrized by $s_{i j}$, is given by

$$
\frac{s_{i j} B\left(R_{j} ; j\right)}{\kappa_{i j}}\left(\frac{C_{i j}}{\gamma}\right)^{\gamma}\left(\frac{H_{i j}}{1-\gamma}\right)^{1-\gamma} .
$$

Commuting costs are expressed in utility terms and given by $\kappa_{i j} \geq 1$, with $\kappa_{j j}=1$. In particular, commuting costs reduce utility except for agents that work where they live. Residential amenities at location $j$ are given by $B\left(R_{j} ; j\right)$, and depend on the number of agents that decide to locate in the neighborhood: a housing externality (as in Rossi-Hansberg, et al., 2010)). We let $B_{j}\left(R_{j} ; j\right)=R_{j}^{\sigma_{j}}$, so that the elasticity of amenities with respect to residents depends on the characteristics of the neighborhood 4 Some urban neighborhoods might depend heavily on some of these externalities, while other more suburban neighborhoods might appeal less to density as an amenity. Throughout, we assume that the congestion force embedded in rising housing demand as the number of residents increases (governed by the parameter $1-\gamma$ ), with corresponding increasing rents, is dominated by the externality in amenities governed by $\sigma_{j}$. That is, we assume that $\sigma_{j}>1-\gamma$ for all $j$. The implication is that neighborhood demand by residents is an increasing function of its number of residents, as we show below.

Individuals have idiosyncratic preferences for residing in location $j$ and working in location $i$. We assume that $s$ is drawn from a Fréchet distribution with scale parameter specific to the residence-work location pair, $\lambda_{i j}>0$, and shape parameter $\theta>0$. Namely,

$$
\operatorname{Pr}\left(s_{i j} \leq s\right)=e^{-\lambda_{i j} s^{-\theta}}
$$

This random idiosyncratic component captures individual-specific reasons that make particular residencework locations appealing beyond those we model directly, such as wages in the place of work compared to rents in the place of residence, or the commuting costs between the two locations. The scale parameter $\lambda_{i j}$ in (6) determines the average idiosyncratic utility from working in $i$ when commuting from $j$, and the shape parameter $\theta$ governs the dispersion of the idiosyncratic component of utility $5^{5}$

Conditional on living in $j$ and working in $i$, the problem of a resident having drawn idiosyncratic utility component $s$ is given by

$$
\begin{aligned}
U_{i j}(s) & =\max _{C_{i j}, H_{i j}} \frac{s B\left(R_{j} ; j\right)}{\kappa_{i j}}\left(\frac{C_{i j}(s)}{\gamma}\right)^{\gamma}\left(\frac{H_{i j}(s)}{1-\gamma}\right)^{1-\gamma} \\
\text { subject to } w_{i} & =q_{j}^{r} H_{i j}(s)+C_{i j}(s),
\end{aligned}
$$

\footnotetext{
${ }^{4}$ Amenities depend on the number of residents because individuals enjoy the ability to interact with neighbors and join community groups, or because the number of residents affects the cost of some community services or infrastructure, or discourages crime. Examples abound but their relevance varies across neighborhoods. Here, $\sigma_{j}$ captures, in reduced form, the heterogeneity in the elasticity of amenities with respect to the number of residents across neighborhoods.

${ }^{5}$ Note that $\lambda_{i j}$ and $\kappa_{i j}$ are, in general, not independently identified. In the application below, we use commuting cost data to determine $\kappa_{i j}$, and identify the $\lambda_{i j}$ needed to match commuting flows.
} 
where $q_{j}^{r}$ is the price of a unit of housing services at $j$. We normalize the price of goods in the city to one. Since we assume that transport costs for goods within the city are negligible, the price of goods in all neighborhoods is the same. Hence,

$$
C_{i j}=\gamma w_{i} \text { and } H_{i j}=\frac{(1-\gamma) w_{i}}{q_{j^{r}}}
$$

Observe that, as the notation recognizes in (8), consumption and housing choices do not depend on the realization of idiosyncratic preferences $s$. Thus the indirect utility function, $U_{i j}(\cdot)$, is simply given by

$$
U_{i j}(s)=\frac{s R_{j}^{\sigma_{j}} w_{i}\left(q_{j}^{r}\right)^{\gamma-1}}{\kappa_{i j}} .
$$

\subsubsection{Commuting Patterns}

Given that the idiosyncratic preferences of individuals are drawn from the distribution in (6), the indirect utility derived in $(9)$ implies that

$$
\operatorname{Pr}\left(U_{i j}<u\right)=e^{-\Phi_{i j} u^{-\theta}}, \text { where } \Phi_{i j}=\lambda_{i j}\left(\frac{R_{j}^{\sigma_{j}} w_{i}\left(q_{j}^{r}\right)^{\gamma-1}}{\kappa_{i j}}\right)^{\theta} .
$$

Standard manipulations then yield an expression for the expected utility of living in $j, U_{j}$, as a function of the weighted sum of the utilities gained from commuting to the different business areas (raised to the $\theta$ ). Namely,

$$
U_{j}=\Gamma\left(\frac{\theta-1}{\theta}\right) R_{j}^{\sigma_{j}}\left(q_{j}^{r}\right)^{\gamma-1}\left(\sum_{i=1}^{J} \lambda_{i j}\left(\frac{w_{i}}{\kappa_{i j}}\right)^{\theta}\right)^{\frac{1}{\theta}}
$$

where $\Gamma$ is the Gamma function.

Let $\pi_{i j}$ represent the proportion of residents living in $j$ that commute to $i$. Then, if $R_{i j}$ is the number of residents in $j$ commuting to the business area of location $i, R_{i j}=\pi_{i j} R_{j}$ and $\sum_{i=1}^{J} \pi_{i j}=1$ for $j=1, \ldots, J$. Since agents choose freely their optimal residence-work pair,

$$
\pi_{i j}=\operatorname{Pr}\left[U_{i j}>\max _{n \neq i}\left\{U_{n j}\right\}\right]
$$

so that 6

$$
\pi_{i j}=\frac{\lambda_{i j}\left(w_{i} / \kappa_{i j}\right)^{\theta}}{\sum_{n=1}^{J} \lambda_{n j}\left(w_{n} / \kappa_{n j}\right)^{\theta}} .
$$

The proportion of those living in $j$ who commute to $i$ for work depends on wages earned in $i$, net of

\footnotetext{
${ }^{6}$ See Monte et al. (2016), among others, for a derivation of this result.
} 
commuting costs, relative to average net wages from commuting elsewhere (raised to the $\theta$ ). Note that the agglomeration effects on amenities by way of $R_{j}$ do not affect commuting patterns from $j$ to $i$ since all residents of $j$ experience the same externality equally. The characteristics of $j$ determine the number of residents, but not where they work.

\subsubsection{The Residential Market}

Condition (8) determines housing consumption for those living in $j$ and commuting to $i, H_{i j}$. Thus, average housing per resident in area $j, H_{j}$, is given by

$$
H_{j}=\sum_{i=1}^{J} \pi_{i j} H_{i j}=\frac{(1-\gamma)}{q_{j}^{r}} \sum_{i=1}^{J} \pi_{i j} w_{i} .
$$

Since $T_{j}^{r}$ denotes the total number of units of "developed" residential land in location $j$, equilibrium in the residential market $j$ implies that

$$
R_{j} H_{j}=T_{j}^{r}
$$

Thus, residential land rents are such that

$$
q_{j}^{r}=\frac{(1-\gamma) R_{j}}{T_{j}^{r}} \sum_{i=1}^{J} \pi_{i j} w_{i} .
$$

Residential land rents increase with the number of residents, decrease with total land developed, and increase with total expenditures by commuters living in the neighborhood, as expected. Observe that $\sum_{i=1}^{J} \pi_{i j} w_{i}$ can alternatively be interpreted as the average wage of location $j$ residents (where the weights are given by the proportion of residents commuting to each area $i$ for work).

We model an open city where individuals can move in and out freely and obtain utility $\bar{u}$ elsewhere in the economy. Hence, if an area within the city has a positive number of residents, it must be the case that $U_{j} \geq \bar{u}$. Using (10), as well as our assumption that $\sigma_{j}>1-\gamma$ for all $j$, we conclude that a neighborhood is viable only if

$$
R_{j} \geq\left(\frac{\bar{u}(1-\gamma)^{1-\gamma}\left\{\sum_{i=1}^{J} \pi_{i j} w_{i}\right\}^{1-\gamma}}{\Gamma\left(\frac{\theta-1}{\theta}\right)\left(T_{j}^{r}\right)^{1-\gamma}\left[\sum_{i=1}^{J} \lambda_{i j}\left(w_{i} / \kappa_{i j}\right)^{\theta}\right]^{\frac{1}{\theta}}}\right)^{\frac{1}{\sigma_{j}+\gamma-1}} .
$$

Conditional on the amount developed residential land, $T_{j}^{r}$, commuting flows, $\pi_{i j}$, and wages, $w_{i}$, the number of residents needed to make a neighborhood viable increases with $\bar{u}$ and with a uniform increase in commuting $\operatorname{costs} \kappa_{i j}$. Conditional on commuting flows and wages, an increase in developed residential land, $T_{j}^{r}$, lowers residential rents, and thus makes the need for residential amenities provided by the number of residents less stringent. Conditional on developed residential land and commuting flows, a uniform increase in wages lowers the number of residents needed to make the neighborhood viable. We denote by $\underline{J}$ the number of 
areas that are viable. These are able to attract the required number of residents and, for these areas, (14) holds with equality. It follows that $J-\underline{J}$ areas have no residents in equilibrium. We discuss multiplicity in the neighborhood equilibrium in detail below.

\subsection{Residential Developers}

There is a large number of small residential developers, none of whom is large enough to internalize residential externalities. Let $h_{j}$ denote the number of units of land developed by residential developers active in neighborhood $j$. Suppose further that the cost associated with developing $h_{j}$ units of land is given by a convex variable cost, $V\left(h_{j}\right)$, that we specify as $V\left(h_{j}\right)=V h_{j}^{v}$ for $v>1$, in addition to a location specific fixed cost, $F_{j}>0$. Residential developers then maximize

$$
\Pi_{j}=\max _{h_{j}} h_{j} q_{j}^{r}-V\left(h_{j}\right)-F_{j}=\max _{h_{j}} h_{j} q_{j}^{r}-V h_{j}^{v}-F_{j},
$$

so that, if $h_{j}>0$,

$$
q_{j}^{r}=v V h_{j}^{v-1} \Leftrightarrow h_{j}=\left(\frac{q_{j}^{r}}{v V}\right)^{\frac{1}{v-1}} .
$$

Developers enter as long as profits are non-negative, so that $h_{j}>0$ if $\Pi_{j} \geq 0$, or alternatively,

$$
h_{j} q_{j}^{r} \geq V h_{j}^{v}+F_{j}
$$

Substituting for $h_{j}$ from the first-order-condition, and residential land rents in equation (13), $\Pi_{j} \geq 0$ implies that

$$
R_{j} \geq \frac{v V\left(\frac{F_{j}}{(v-1) V}\right)^{\frac{v-1}{v}}}{(1-\gamma) \sum_{i=1}^{J} \pi_{i j} w_{i}} T_{j}^{r} .
$$

Hence, an individual developer will only invest in developing residential land if the density of residents, $R_{j} / T_{j}^{r}$, which determines residential prices, is large enough relative to the local fixed costs, $F_{j}$. These costs would typically include getting the land ready for residential development, the installation of utilities such as water services and sanitary sewer systems, the building of access roads and sidewalks if needed, as well the handling of permits and legal fees, the design of the development, etc. Condition (17) implies that the number of residents required for developers to be willing to invest in a given location is increasing in the amount of developed residential land, in equilibrium, and in the fixed costs of developing residential properties in that location. This is intuitive since developers need high enough demand to cover the fixed costs, given the increasing returns in their technology.

Equilibrium in the residential market implies that

$$
n_{j} h_{j}=R_{j} H_{j}=T_{j}^{r} \leq \bar{T}_{j}^{r}
$$


where $n_{j}$ is the number of active residential developers and $\bar{T}_{j}^{r}$ is the upper bound on residential development in $j$, assumed to be dictated by zoning ordinance. Since total developed land is given by $T_{j}^{r}=n_{j} h_{j} \leq \bar{T}_{j}^{r}$, substituting from (16), we obtain that the number of active developers is given by

$$
n_{j}=\frac{\left(T_{j}^{r}\right)^{\frac{v}{v-1}}}{\left(\frac{(1-\gamma)}{v V} R_{j} \sum_{i=1}^{J} \pi_{i j} w_{i}\right)^{\frac{1}{v-1}}}
$$

if condition (17) is satisfied, and $n_{j}=0$ otherwise.

\subsection{Neighborhood Residential Equilibrium}

Having described the actions of agents in our economy, we are ready to discuss the determination of the number of residents, $R_{j}$, and the amount of residential land, $T_{j}^{r}$, in different neighborhoods $j \in J$, given the characteristics of the city summarized by the model's parameters, the utility level $\bar{u}$, wages $\left\{w_{i}\right\}_{1}^{J}$, and commuting patterns, $\left\{\pi_{i j}\right\}_{11}^{J J}$. The two key conditions in this respect are those that determine resident entry, (14), and developer entry, (17).

In viable neighborhoods, where the number of residents is positive, a neighborhood equilibrium always makes agents indifferent among their location choices, which implies that condition (14) holds with equality. As discussed above, this condition implies a negative relationship between the number of residents, $R_{j}$, and total developed land in the neighborhood. In Figure 4, we illustrate this relationship using the downward sloping curve labeled "Resident Entry".

Consider now developer entry. As explained above, developers enter if condition (17) is satisfied. In a viable neighborhood, either condition (17) is satisfied with equality, or the residential zoning constraint binds, so that $T_{j}^{r}=\bar{T}_{j}^{r}$. Consider first the former case, which is depicted in Figure 4. The relationship in (17) is a straight upward slopping line starting from the origin. The crossing between the two curves in Figure 4 determines one of the neighborhood equilibria. 7 In this case, the zoning restriction does not bind and we refer to such a neighborhood equilibrium as an area that is partially developed or semi-developed. This equilibrium is depicted by one of the red dots in Figure 4.

The crossing between these two curves could be such that the resulting amount of developed land violates the zoning restriction. In that case, the number of residents is determined by the crossing between the zoning constraint and the resident entry condition. The developer entry condition is then satisfied with strict inequality and developers potentially make positive profits. Other developers might wish to enter the neighborhood, given the number of residents, but the amount of residential land available for development is exhausted. We refer to neighborhoods that are in this situation as fully developed areas. The equilibrium

\footnotetext{
${ }^{7}$ The diagrams in Figure 4 above and Figure 5 below take as given wages and commuting patterns and so cannot be used alone to make certain arguments. For example, neighborhood equilibrium stability arguments, where a new resident or developer enters or leaves (as an out of equilibrium deviation), would change wages and commuting patterns and thereby shift the resident and developer entry conditions themselves.
} 


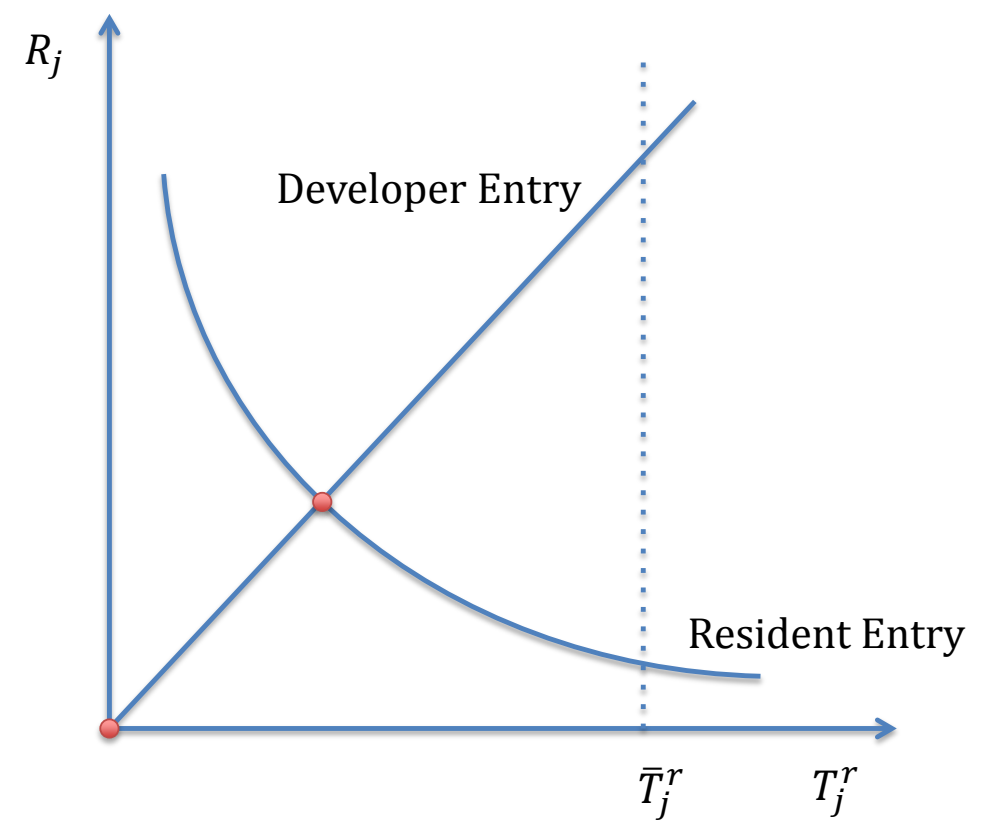

Figure 4: Determination of $R_{j}$ and $T_{j}^{r}$ when $T_{j}^{r}<\bar{T}_{j}^{r}$

is depicted as one of the red dots in Figure 5 .

Independently of whether the zoning constraint is binding or not, conditional on wages and commuting patterns, an equilibrium with developed land and positive numbers of residents always exists and is unique. The reason is that the developer entry condition is continuous, upward slopping, linear, and starts from the origin, while the resident entry condition is continuous, downward sloping, positive, and bounded away from zero. The Intermediate Value Theorem then implies that the two curves cross, and the shape of the curves imply that they cross only once, so that a neighborhood equilibrium with positive $R_{j}$ and $T_{j}^{r}$ exists and is unique.

In either case, however, there always exists an additional equilibrium that describes a non-viable neighborhood, specifically an equilibrium where $R_{j}=T_{j}^{r}=0$. The reason is that residential externalities are such that if $R_{j}=0$, the utility that agents derive from living in the neighborhood is also zero. That is, $B_{j}(0 ; j)=0$. At the same time, when $R_{j}=0$ developers supply zero developed land. Therefore, the nonviable allocation is always an equilibrium. It follows that every neighborhood in the city, independent of its fundamental characteristics, might be in an equilibrium where residents and developers coordinate and make it viable, or one in which they fail to coordinate and the neighborhood is vacant. Put another way, in order for an area to coordinate on the equilibrium with positive development, enough developers have to expect that others will also invest, and that sufficiently many residents will populate the neighborhood. This in turn requires that enough residents expect other residents to want to live in the developed neighborhood. 


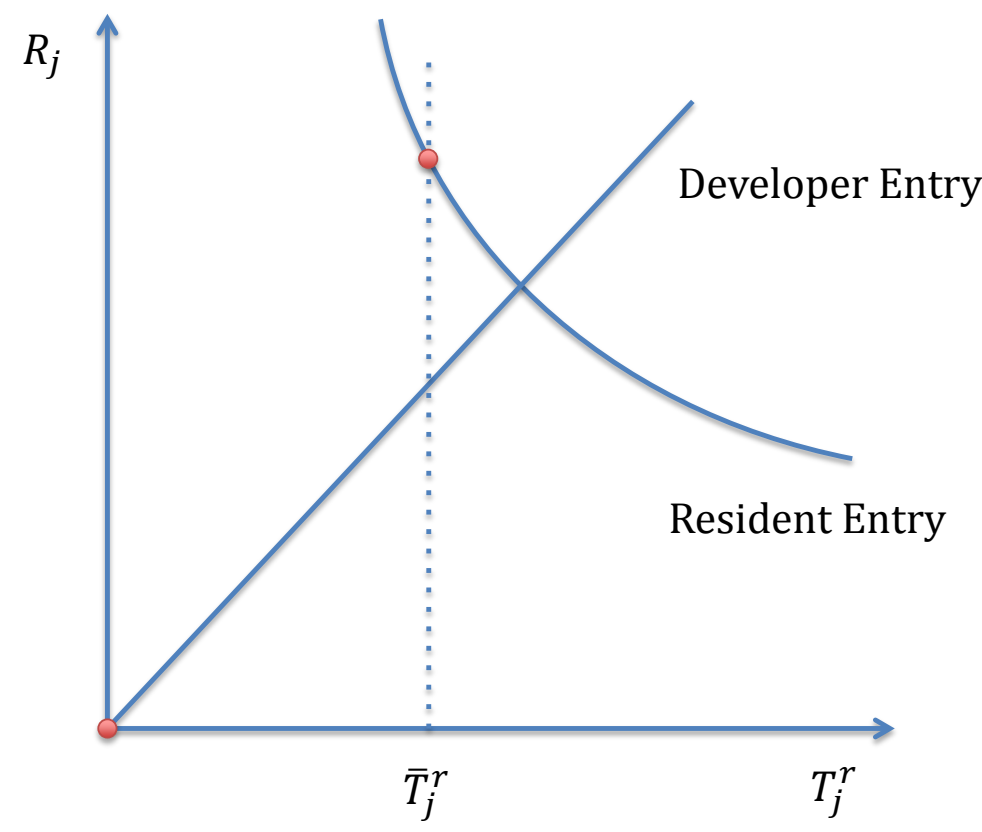

Figure 5: Determination of $R_{j}$ and $T_{j}^{r}$ when $T_{j}^{r}=\bar{T}_{j}^{r}$

In the coordinated equilibrium, the fundamental characteristics of a given neighborhood ultimately determine the number of residents and amount of developed land required to remain viable. Neighborhoods with relatively good fundamentals (e.g. a low $F_{j}$, or uniformly low $\kappa_{i j}$ ) require small numbers of residents and developed land to become or remain viable. In contrast, neighborhoods with poor fundamentals need much more coordination as the required magnitude of the external effect on amenities is larger to compensate for the poor fundamentals. We now proceed to solve for the values of $R_{j}$ and $T_{j}^{r}$ in the coordinated equilibrium for the cases of fully and partially developed areas.

\subsubsection{The Case of Fully Developed Areas}

Consider first the case in which $T_{j}^{r}=\bar{T}_{j}^{r}$. We let $\Omega^{F}=\left\{j \mid T_{j}^{r}=\bar{T}_{j}^{r}\right\}$ denote the set of all locations that end up fully developed in equilibrium. This is the case depicted in Figure 5. Since residents can move freely across different areas of the city, condition 14 evaluated at $\bar{T}_{j}^{r}$, has to hold with equality. Namely,

$$
R_{j}=\left(\frac{\bar{u}(1-\gamma)^{1-\gamma}\left\{\sum_{i=1}^{J} \pi_{i j} w_{i}\right\}^{1-\gamma}}{\Gamma\left(\frac{\theta-1}{\theta}\right)\left(\bar{T}_{j}^{r}\right)^{1-\gamma}\left[\sum_{i=1}^{J} \lambda_{i j}\left(w_{i} / \kappa_{i j}\right)^{\theta}\right]^{\frac{1}{\theta}}}\right)^{\frac{1}{\sigma_{j}+\gamma-1}}
$$


From equation 13 , we also know that for all $j \in \Omega^{F}$,

$$
q_{j}^{r}=(1-\gamma) \frac{R_{j}}{\bar{T}_{j}^{r}} \sum_{i=1}^{J} \pi_{i j} w_{i} .
$$

In these locations, since all available land for potential development is already built up, developers may earn strictly positive rents, and so condition (17) will hold with strict inequality, as depicted in Figure 5. Furthermore, residential land rents in fully developed tracts are determined by demand for residential properties rather than the cost of developing residential housing.

\subsubsection{The Case of Partially Developed Areas}

Consider now the case of neighborhoods in which the zoning constraint is not binding, so $T_{j}^{r}<\bar{T}_{j}^{r}$. We denote the set of these locations as $\Omega^{S}=\left\{j \mid T_{j}^{r}<\bar{T}_{j}^{r}\right\}$ and refer to them as semi-developed or partially developed. This is the case depicted in Figure 4. As discussed above, in this case, both (14) and (17) hold with equality. Furthermore, equations (13) and (17) may be combined to give a simple expression for (per unit) residential prices,

$$
q_{j}^{r}=\nu V\left(\frac{F_{j}}{(v-1) V}\right)^{\frac{v-1}{v}} .
$$

Thus, rents across partially developed neighborhoods vary only because of variation in the fixed costs of developing residential land.

Solving for $T_{j}^{r}$ from equations 14 and 17 gives

$$
T_{j}^{r}=\left(\frac{\bar{u}(1-\gamma)^{1-\gamma}\left[\left(\frac{(v-1) V}{F_{j}}\right)^{\frac{v-1}{v}}\left(\frac{1-\gamma}{v V}\right)\right]^{\sigma_{j}+\gamma-1}}{\Gamma\left(\frac{\theta-1}{\theta}\right)\left\{\sum_{i=1}^{J} \lambda_{i j}\left[w_{i} / \kappa_{i j}\right]^{\theta}\right\}^{\frac{1}{\theta}}}\right)^{\frac{1}{\sigma_{j}}} \sum_{i=1}^{J} \pi_{i j} w_{i},
$$

where $T_{j}^{r}<\bar{T}_{j}^{r}$. Hence, $T_{j}^{r}$ is increases with $\bar{u}$, and decreases with $F_{j}$. Note also that a uniform increase in wages, $\left\{w_{i}\right\}_{1}^{J}$, that leaves commuting patterns constants per equation $\sqrt{11}$, decreases $T_{j}^{r}$ if $\sigma_{j}<1$, leaves it unchanged if $\sigma_{j}=1$, and increases developed residential land if $\sigma_{j}>1$. In our quantitative application to Detroit data below, we obtain that $\sigma_{j}<1$ for virtually all neighborhoods, so that residential development, $T_{j}^{r}$, decreases with wages 8 This finding is natural; consider a city in which many neighborhoods are not viable because coordination has failed. Since employment opportunities are still available, equilibrium wages will tend to to be high throughout the city since residential rents in viable neighborhoods are relatively high. The resulting lower $T_{j}^{r}$ then implies that the level of coordination needed to develop neighborhoods is then lower, all else equal. This mechanism does not necessarily guarantee that coordination will be more pervasive;

\footnotetext{
${ }^{8}$ In the quantitative application to Detroit that we present in the next section, the mean of $\sigma_{j}$ is 0.570 , with a standard deviation of 0.046 , a minimum of 0.446 and a maximum of 1.024 . We only found one census tract for which $\sigma_{j}>1$.
} 
such an outcome would depend in part on the factors affecting equilibrium selection, including the policies we discuss below. However, all else equal, any attempt to coordinate the relevant agents is likely to be less costly in such a scenario. The response of the neighborhood equilibrium to a uniform increase in wages is illustrated in Figure 6 .

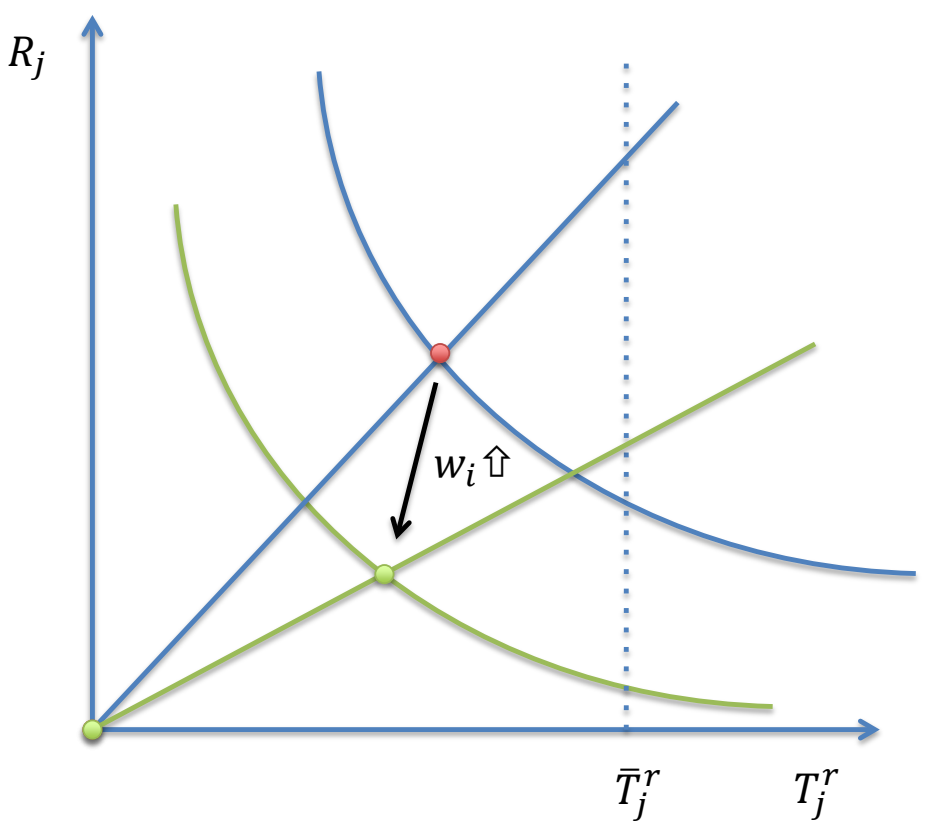

Figure 6: Neighborhood equilibrium and a uniform increase in wages

Another interesting comparative static relates to decreases in $\kappa_{i j}$, particularly given the availability of a vast set of limited access highways that reduce commuting costs between Detroit's central business district and its suburbs. A decline in some $\kappa_{i j}$ reduces $T_{j}^{r}$. Hence, it is conceivable that these highways had the effect of reducing coordination issues in the suburbs and, through general equilibrium effects on wages, increasing the level of coordination needed in neighborhoods close to downtown areas. Figure 7 illustrates the change in neighborhood equilibrium resulting from changes in commuting costs.

\subsection{The City Equilibrium}

The above discussion determines $R_{j}$ and $T_{j}^{r}$ given $\bar{u}$, wages $\left\{w_{i}\right\}_{1}^{J}$, and commuting patterns, $\left\{\pi_{i j}\right\}_{11}^{J J}$. We now proceed to discuss the citywide equilibrium where wages and commuting patterns are endogenous. Since transport costs of goods are assumed to be negligible, and we have normalized the price of goods throughout the city to one, the goods market equilibrium is guaranteed by Walras' law. The only remaining market to clear is the labor market.

Equilibrium in the labor market is guaranteed when, for each business area $i \in J$, labor supply is equal 


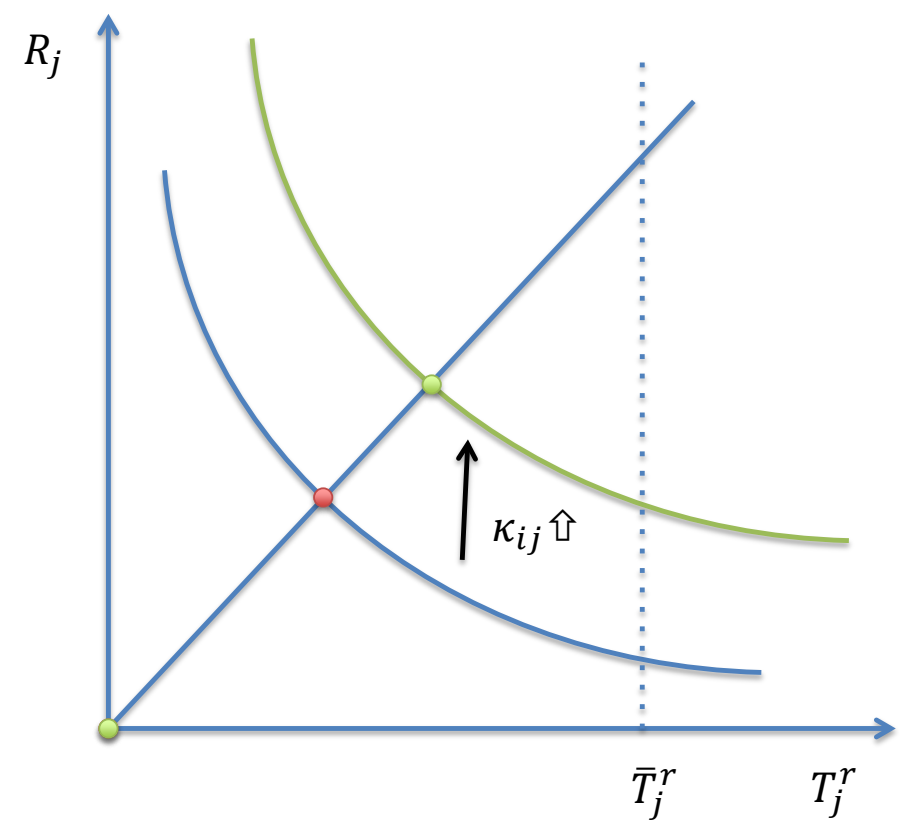

Figure 7: Neighborhood equilibrium and an increase in commuting costs

to labor demand. Labor supply in neighborhood $i$ is the sum of the flows of workers commuting from all neighborhoods, specifically $\sum_{j=1}^{J} \pi_{i j} R_{j}$. Labor demand is in turn given by firms' choices in each location $i$ derived in (4). Hence, equilibrium in the labor market is guaranteed by

$$
L_{i}=\sum_{j=1}^{J} \pi_{i j} R_{j} \text { for all } i \in J,
$$

or

$$
\left(\frac{A_{i} \beta}{w_{i}}\right)^{\frac{1}{1-\beta-\alpha}} T_{i}^{b}=\sum_{j=1}^{J} \pi_{i j} R_{j} \text { for all } i \in J .
$$

Labor demand on the left-hand side is decreasing in $w_{i}$ given our maintained assumption that $1-\beta>\alpha$. Labor supply on the right-hand side, in contrast, is more difficult to characterize since it depends on the number of developed tracts, $\underline{J}$, which itself depends on the distribution of wages in equilibrium. In general, however, higher wages will increase labor supply by attracting more residents to the city and to nearby residential neighborhoods, and by lowering the number of residents needed to make neighborhoods viable.

We can substitute (14) with equality for the $\underline{J}$ viable neighborhoods in $(24)$, and set $R_{j}=0$ for the remaining neighborhoods, to obtain a system of equations in $w_{i}, i=1, \ldots, J$, given the amount of land in business and residential uses as well as commuting patterns throughout the city. The amount of land devoted to business use is exogenous, $T_{i}^{b}$, and residential land in viable neighborhoods, $T_{j}^{r}$, is given by equation 23 . 
Finally, we can substitute equation (11), that determines commuting patterns as a function of wages, for $\pi_{i j}$ in equations (23) and (24). The result is a system of $J$ equations in the $J$ unknown wages. To the extent some subset $I \subset J$ of tracts does not contain any business activity, $T_{i}^{b}=0$ and $\pi_{i j}=0$ in those tracts, so that (24) holds trivially for $i \in I$ within this system of equations. The solution determines the citywide equilibrium. Appendix A provides a description of the solution and algorithm we use to compute equilibria.

\subsubsection{A Closed City}

So far we have assumed that individuals can flow freely in and out of the city: an open city. In some of the exercises we present below, we wish to consider the case of a closed city whereby total population, $R=\sum_{j=1}^{J} R_{j}$, remains constant. In such a case, instead of having a fixed utility level determined in the wider economy, we let $\bar{u}$ be determined endogenously so that total population is equal to the observed total population in the city. We present several exercises with this constraint imposed in the on-line appendix.

\section{Quantitative Application}

We make use of current data on various aspects of Detroit to quantify the spatial urban framework described above. The benchmark year in our analysis is 2014 . Our analysis is carried out at the census tract level, since this is the smallest spatial unit for which we can assemble an accurate and complete matching dataset. Thus an area or neighborhood in the theory above is associated with a census tract in Detroit's metropolitan area. Our analysis covers the 297 census tracts in Detroit, as well as the surrounding adjacent metro area (Wayne County, Oakland County, and Macomb County), which includes 866 additional tracts. We exclude 12 tracts owing to missing or problematic data, and carry out the analysis on the remaining 1151 tracts. We aim to find values of the underlying characteristics of neighborhoods (amenities, technology, fixed costs, externalities and residential zoning) for each one of these tracts that rationalize, in our framework, the available data on Detroit. Below, we give a brief description of the various data sources that provide information on the variables of interest, and a detailed discussion of all data definitions and manipulations is provided in the on-line appendix.

The data on the number of residents, $R_{j}$, workers, $L_{j}$, and pairwise commuting patterns, $\pi_{i j}$, is available from the Longitudinal Employer-Household Dynamics (LEHD), Origin-Destination Employment Statistics (LODES). This data is broken down into different classifications for job types including all private and federal jobs. Wages, $w_{j}$, are primarily determined using hourly wage bins provided by the LODES data set, and are also complemented with data from the ZIP Business Patterns published by the United States (US) Census Bureau. The complement, in particular, provides an additional bin at the upper end of the distribution, with an upper bound set to 87560 dollars per year.

Information on developed residential land, $T_{j}^{r}$, commercial land, $T_{j}^{b}$, and residential prices, $q_{j}^{r}$, is available at the parcel level from several different sources of microdata. The sources include Detroit's Assessment 
Office, Wayne County's Office of Equalization and Assessment, Oakland County's Office of Economic Affairs and Community Development, and CoreLogic for Macomb county.

Our primary source for measuring commuting costs between census tracts, $k_{i j}$, is Google Analytics. In particular, the Application Programming Interface (API) for Google Maps Distance allows the user to specify one-among-many different possible travel methods between any two coordinates (or addresses), $1151^{2}$ such pairs in our case. We consider the fastest driving route suggested by the API and do not impose any restrictions, such as avoiding major highways or tolls. Data on both time and distance take into account historical traffic patterns and geography by way of existing road networks 9

Finally, we make use of data on active building and demolition permits from Detroit's Demolition Program and Detroit's Buildings, Safety, and Environment Department. This information helps us identify the number of unique contractors in a given census tract, $n_{j}$, with at least one currently active permit. An active permit is any permit issued up until our benchmark year, 2014, and still active from that year onward.

\subsection{Vacant, Partially Developed, and Fully Developed Locations}

An important step in matching our model to observed allocations in the city of Detroit is to designate particular tracts as fully developed, partially developed, or empty or vacant. In particular, we need to partition the complete set of tracks, $\Omega$, into sets $\Omega=\Omega^{F} \cup \Omega^{s} \cup \Omega^{v}$, where $\Omega^{v}$ denotes the set of vacant tracts. Note that this classification refers only to residential development in the different tracts. In Detroit, all tracts (except for one) contain business areas with positive measured employment.

\subsubsection{Vacant Tracts}

We start by describing our methodology to select the tracts $j \in \Omega^{v}$. Our analysis relies on a key survey, known as the Motor City Mapping project (MCM), involving a collaboration of private and public entities. This project was developed in order to label blighted and abandoned properties in Detroit for removal or revitalization. By collecting this data, the goal was to provide policy-makers and non-profit associations with information that would guide urban policies aimed at attracting new residents to the city.

The Detroit Blight Removal Task Force and two other organizations, (Loveland Technologies and Data Driven Detroit (D3)), led a physical survey of Detroit's 380,000 parcels of land on behalf of MCM. This physical survey was an expansion of the Residential Parcel Survey conducted in 2009 for 135,000 residential properties in the city of Detroit and now covers commercial properties and parcels used for other purposes (e.g. parks, parking, etc.)

Blighted areas identified by the MCM survey tend to be dominated by vacant lots and unoccupied structures. Consistent with the MCM survey, we classify vacant census tracts in the context of our model

\footnotetext{
${ }^{9}$ Interestingly, commute data between census tracts is not entirely symmetric in the sense that $k_{i j}$ can differ significantly from $k_{j i}$. For instance, one way streets and other asymmetries in the road network can lead to differences of ten minutes or more for about 5800 commute pairs.
} 
(i.e. associated with the no-development residential equilibrium) according to the following three criteria:

1. The percentage of parcels in a census tract classified as vacant (i.e. with no physical structure) is greater than or equal to 50 percent AND

2. The percentage of residential properties in a census tract labeled empty or potentially empty is greater than or equal to 30 percent OR

3. The percentage of commercial properties in a census tract labeled empty or potentially empty is greater than or equal to 30 percent

Using these thresholds, we arrive at 17.5 percent of census tracts in Detroit being associated with the residential no-development case, which closely matches the percentage of blighted parcels identified by the MCM survey, (22 percent) ${ }^{10}$ The resulting $\Omega^{v}$ set includes 52 tracts. These are the tracts that we identify as currently being in the non-coordinated equilibrium, or vacant in terms of residents. The location of these tracts is presented in Figure 3 in Section 2, As discussed there, these tracts are closely associated with the expansion of the city of Detroit before 1930 and form a ring just outside the business district of the city.

\subsubsection{Fully versus Partially Developed Tracts}

Of the census tracts not considered vacant, the model distinguishes between tracts that are fully developed, $\Omega^{F}=\left\{j \mid T_{j}^{r}=\bar{T}_{j}^{r}\right\}$, and those that are partially developed, $\Omega^{S}=\left\{j \mid T_{j}^{r}<\bar{T}_{j}^{r}\right\}$. Because the D3 survey, which provides the percentage of empty parcels, is only available for the 297 census tracts within Detroit proper, we have to impute this allotment for the remaining census tracts of Macomb, Oakland, and Wayne Counties.

We do so by fitting a linear model of the determinants of the percentage of empty parcels in tracts within Detroit proper, and then use it to estimate the percent of empty parcels in all tracts of the surrounding the suburbs. The linear specification that we fit includes tract population, $R_{j}$, developed residential land, $T_{j}^{r}$, average census tract wages, and commuting costs from downtown. The model's adjusted $R^{2}$ is 0.59 . Using data on these neighborhood characteristics, as well as the coefficient estimates, we estimate the fraction of empty parcels in each tract in the suburbs 11 As a benchmark, we then designate a tract where more than $2 / 3$ of its parcels are occupied as being fully developed. Other tracts with less than $2 / 3$ occupancy are considered only partially developed. Figure 3 in Section 2 presents the resulting selection of tracts (for

\footnotetext{
${ }^{10} \mathrm{DFC}$, in developing a strategic framework to revitalize Detroit, assessed that 17 percent of its parcels are vacant.

${ }^{11}$ We estimate

$$
\ln \% \text { Vacant }_{j}=\omega_{1}+\omega_{2} R_{j}+\omega_{3} T_{j}^{r}+\omega_{4} \bar{w}_{j}+\omega_{5} \kappa_{1 j}+\varepsilon_{j}
$$

where $\%$ Vacant $_{j}$ is the ratio of vacant parcels and parcels with unoccupied structures to the total number of parcels, and $\kappa_{1 j}$ denotes the distance from $j$ to the CBD (labeled as tract 1 in our analysis). The resulting coefficients (with standard errors in parenthesis) are $\omega_{1}=6.26(0.95), \omega_{2}=-0.0012(0.0002), \omega_{3}=-0.38(0.2), \omega_{4}=-0.00015(0.000024)$, and $\omega_{5}=-0.06$ (0.0081). The regression has 242 observations and yields an adjusted $R^{2}$ of 0.59 .
} 
ease of presentation we leave out some of the suburban tracts) ${ }^{12}$ As can be easily appreciated in the figure, most of Detroit proper is designated as partially developed, while most of the suburbs as fully developed.

\subsection{Parameters Values}

The model features three different sets of parameters that differ in their dimensionality: citywide, neighborhood specific, and bilateral across neighborhoods. The city-wide parameters $(\alpha, \beta, \gamma, v)$ are matched to estimates in the literature, except for $\theta$ and $V$, that we set to match respectively the slope of the gravity equation, as in Monte et al. (2016), and the distribution of active contractors across neighborhoods. We normalize $\bar{u}$ to 1 . The neighborhood parameters $\left(A_{j}, F_{j}, \sigma_{j}, \bar{T}_{j}^{r}, \bar{T}_{j}^{b}\right)$ are determined so as to match four neighborhood characteristics, $\left(w_{j}, q_{j}^{r}, R_{j}, T_{j}^{b}\right)$. Since tracts in equilibrium are either partially or fully developed, with different residential pricing implications, $F_{j}$ and $\bar{T}_{j}^{r}$ cannot both be inferred from the data for the same tract. Specifically, as explained below, $F_{j}$ and $\bar{T}_{j j}^{r}$ may be inferred for $j \in \Omega^{S}$ and $j \in \Omega^{F}$ respectively. Therefore, conditional on tract classification and citywide parameters, characteristics of the city are exactly matched as equilibrium benchmark allocations, and exactly identify the neighborhood parameters. Finally, we choose the bilateral amenity matrix, $\lambda_{i j}$ to match bilateral commuting patterns in the data, $\pi_{i j}$, conditional on observed commuting costs, $\kappa_{i j}$.

We set the values of the city-wide parameters using standard sources in the literature. Table 1 presents the values of the five citywide parameters and the relevant source. We estimate two parameters either because the literature does not offer a clear counterpart or because the context of Detroit is somewhat unique. The first of these involve the parameter $V$, which governs the level of the variable cost of residential construction. Combining equations $\sqrt{19}$ and $(13)$, we know that the number of residential developers in viable neighborhoods is

$$
n_{j}=(\nu V)^{\frac{1}{\nu-1}}\left(q_{j}^{r}\right)^{\frac{\nu}{1-\nu}}(1-\gamma) R_{j} \sum_{i=1}^{J} \pi_{i j} w_{i} .
$$

Given our data, for this purpose $\left(q_{j}^{r}, R_{j}, w_{i}, \pi_{i j}\right)$, and the parameters in Table 1 , we determine $V$ to match the mean of the distribution describing the number of contractors with active permits in the benchmark year, 2014, across partially developed census tracts. These data are available from the Detroit Demolition Program and Buildings, Safety Engineering and Environmental Department. The resulting mean of $n_{j}$ in the data and model is 9.25 contractors with active permits per census tract. We can also compare the standard deviation of $n_{j}$ in the data and model. The standard deviation of $n_{j}$ in the data is 4.52 and that implied by the model is 4.51 , a remarkable similarity given that we do not target this moment.

The second parameter that we estimate within the model is $\theta$, which governs the elasticity of commuting flows with respect to commuting costs. In particular, from equation (11), we can express commuting patterns

\footnotetext{
${ }^{12}$ We choose a $2 / 3$ threshold to define fully developed census tracts in our benchmark. While this threshold is somewhat arbitrary, it acknowledges that desirable development also requires some empty and recreational areas. To the extent that obtaining development rights, permits, and residents approval, becomes more difficult as fewer tracts remain unoccupied or empty, increases in housing demand will start driving up rents in existing housing services.
} 


\begin{tabular}{ccc}
\hline \hline Parameter & Value & Source \\
\hline$\alpha$ & 0.06 & Ciccone and Hall (1996) \\
$\beta$ & 0.80 & Ahlfeldt, et. al (2015) \\
$\gamma$ & 0.76 & Davis and Ortalo-Magné (2011) \\
$\theta$ & 8.34 & Gravity equation for commuting \\
$\nu$ & 2.50 & Ahlfeldt and McMillen, (2015) \\
$V$ & $174,941,657$ & Equation for mean number of contractors \\
\hline
\end{tabular}

Table 1: Citywide parameter values and sources

in terms of the Head and Ries (2001) index as

$$
\frac{\pi_{i j}}{\pi_{j j}}=\frac{\lambda_{i j}\left(w_{i} / \kappa_{i j}\right)^{\theta}}{\lambda_{j j}\left(w_{j} / \kappa_{j j}\right)^{\theta}}
$$

Similarly to Monte et al. (2016), we estimate the following equation,

$$
\log \left(\frac{\pi_{i j}}{\pi_{j j}}\right)=-\theta \log \left(\frac{\kappa_{i j}}{\kappa_{j j}}\right)+\mu_{i}+\mu_{j}+\lambda_{i j}
$$

which, given commute costs data (distance or time), and fixed origin and destination effects, $\mu_{i}$ and $\mu_{j}$, allows us to estimate $\theta$. We invoke standard mean independence assumptions on the error term $\lambda_{i j}$, which in this case governs the mean of the idiosyncratic bilateral amenity. Here, $\kappa_{i j} \in[1, \infty)$. Thus, if $\pi_{i j}=0$, then either $\lambda_{i j}=0$ or $\kappa_{i j} \rightarrow \infty$.

The resulting estimates of $\theta$ using different measures of commuting costs are shown in Table 2. We present results using $\kappa_{i j}$ measured by the straight-line distance between the centroid of $i$ and $j$. This yields an estimate of $\theta$ of 6.57. If we rely instead on distance estimates obtained from Google Analytics, we obtain a lower estimate of $\theta$ given by 4.62 . This measure of distance is arguably more accurate since it takes into account the road infrastructure and geography in the city of Detroit. Our estimate for $\theta$ using this distance measure is very similar to that obtained by Monte, et al. (2016) using commuting patterns across counties, 4.43. We also compiled data on an alternative measure of commuting costs based on all pairwise commute times between census tracts. Such estimates are arguably more pertinent within a city since they take into account road speed and average traffic ${ }^{13}$ Using this alternative measure of commuting costs, we estimate a larger elasticity for $\theta$ at 8.34. This is the value that we use in our benchmark calibration.

Given $\theta$, we may immediately obtain $\lambda_{i j}$ as the residual in equation 25. We further set $T_{j}^{b}=\bar{T}_{j}^{b}$ for all $j \in \Omega$. Hence, the neighborhood specific parameters left to determine are $\left(A_{j}, F_{j}, \sigma_{j}, \bar{T}_{j}^{r}\right)$. Given data on residential prices, $q_{j}^{r}$, residential population, $R_{j}$, wages, $w_{i}$, and commute flows, $\pi_{i j}$, we recover either the

\footnotetext{
${ }^{13}$ These issues are likely less relevant across counties than within cities, which explains why Monte et al. (2016)'s estimate using distance is closer to our estimate using distance rather than time.
} 


\begin{tabular}{cccc}
\hline \hline & Straight-Line Distance & Google Distance & Google Time \\
\hline$\theta$ & 6.57 & 4.62 & 8.34 \\
S.E. & $(0.017)$ & $(0.013)$ & $(0.022)$ \\
\hline Work F.E. & yes & yes & yes \\
Home F.E. & yes & yes & yes \\
Observations & $1,187,423$ & $1,187,423$ & $1,187,423$ \\
$R^{2}$ & 0.39 & 0.37 & 0.38 \\
\hline
\end{tabular}

Table 2: Gravity equation estimation using different measures of commuting

development fixed costs $F_{j}$, for partially developed neighborhoods, or the upper bound on land development, $\bar{T}_{j}^{r}$, for fully developed tracts. The observed allocations are informative in different ways depending on whether a tract is partially or fully developed, which allows us to recover one parameter or the other but not both, depending on the tract's current classification. In particular, we can use equation (20), in the case of fully developed tracts, to solve for $\bar{T}_{j}^{r}$ using information on $\left(w_{j}, q_{j}^{r}, R_{j}, \pi_{i j}\right)$ and $\gamma$. Alternatively, we use citywide parameters and $q_{j}^{r}$ to obtain $F_{j}$ using equation 22 for partially developed tracts. The resulting values of $F_{j}$ are presented in Figure 8 and show a wide range of values. Naturally, we find the highest fixed costs in downtown Detroit.

To compute $\sigma_{j}$, observe that equation (14) implies that

$$
\sigma_{j}=\left(\frac{1}{\ln \left(R_{j}\right)}\right) \ln \left(\frac{\bar{u}(1-\gamma)^{1-\gamma}\left\{\sum_{i=1}^{J} \pi_{i j} w_{i}\right\}^{1-\gamma}}{\Gamma\left(\frac{\theta-1}{\theta}\right)\left(T_{j}^{r}\right)^{1-\gamma}\left[\sum_{i=1}^{J} \lambda_{i j}\left(w_{i} / \kappa_{i j}\right)^{\theta}\right]^{\frac{1}{\theta}}}\right)-\gamma+1,
$$

where $T_{j}^{r}=\bar{T}_{j}^{r}$ when $j \in \Omega^{F}$ and $T_{j}^{r}$ is given by equation 23 when $j \in \Omega^{S}$. The resulting values for $\sigma_{j}$ are presented in Figure 9. These average to 0.57 across neighborhoods and do not exhibit large variations. The minimum value is 0.446 which guarantees that $\sigma_{j}>1-\gamma=0.24$; that is, this restriction is naturally satisfied in our model, given observed Detroit allocations, without being explicitly imposed.

The final step is to choose neighborhood productivity parameters, $A_{j}$, to match the observed distribution of wages across census tracts in the benchmark equilibrium. We use the labor market clearing condition in (24) to set

$$
A_{i}=\frac{w_{i}}{\beta}\left(\frac{1}{T_{i}^{b}} \sum_{j=1}^{J} \pi_{i j} R_{j}\right)^{1-\beta-\alpha}
$$

given the data and parameters discussed above in addition to $T_{i}^{b}$ for all $j$. Figure 9 presents the computed values of $A_{j}$. The results are very intuitive. Productivity is high in downtown Detroit, but it declines dramatically in some of the surrounding areas. It increases again in some of the suburbs where automobile industry plants are located, such as in Dearborn, MI. 


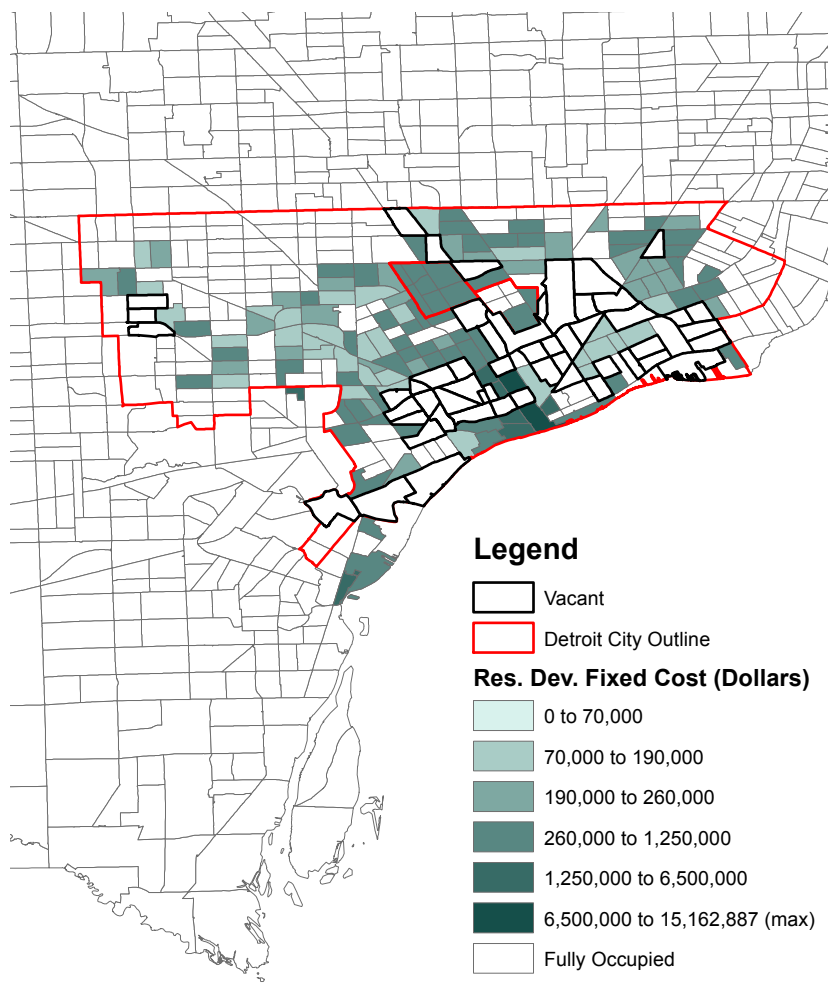

Figure 8: Residential development fixed cost, $F_{j}$, in the baseline quantification

\section{Coordinating Vacant Residential Tracts}

The quantification of our theoretical model above allows us to exactly match the current configuration of Detroit, and its surrounding counties, given the tract level data we use. Thus, we now make use of our framework to quantify the effects of alternative, counterfactual, urban configurations of the city. We identified 52 census tracts as being vacant, in the sense of being empty of residents, although we also saw that all tracts (but one) contain some measure of business activity. The model rationalizes the existence of these vacant neighborhoods as those that have failed to achieve coordination and that find themselves, therefore, in the neighborhood equilibrium with no residents and no residential development. In this section, we compute the value of a change to the alternative equilibrium for these neighborhoods, whereby these areas coordinate into the equilibrium with positive amounts of residential development and residents.

Most of the policies that have been advocated to revitalize the city of Detroit involve a re-configuration of sorts, including a degree of coordination and government involvement to revitalize specific parts of the city. Our framework can help quantify the effects and gains from these policies, and can aid in determining the set of census tracts where these policies might be most successful and valuable. There are a variety of policies that could change equilibrium selection in a neighborhood. Our model, as with many models that feature multiple equilibria, is not explicit about equilibrium selection. As with these other applications, 

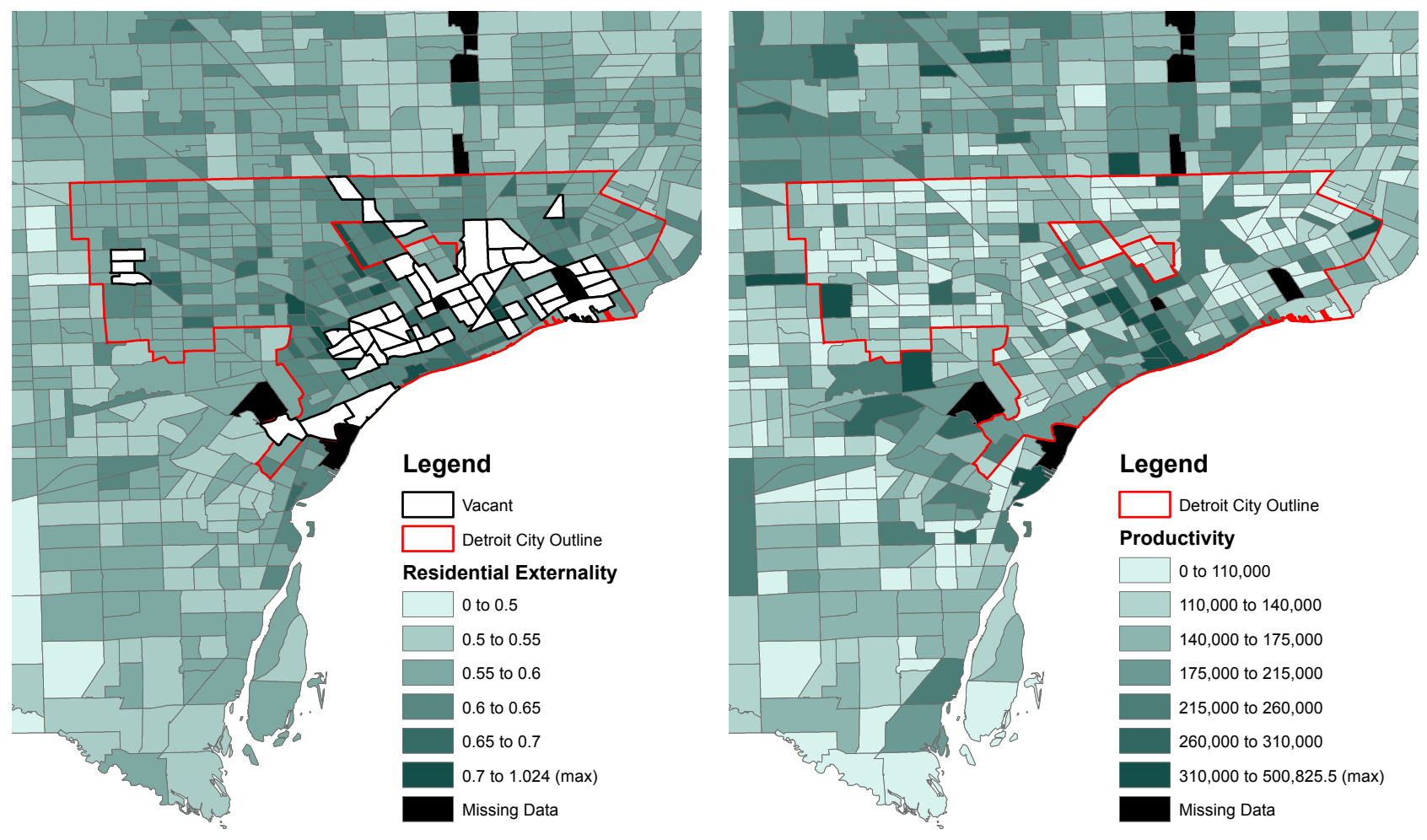

Figure 9: Residential externality, $\sigma_{j}$, and productivity $A_{j}$, in the baseline quantification

however, we can think about policies that can eliminate the degenerate equilibrium, in our case the zero residential development neighborhood allocation. ${ }^{14}$ An example of such a policy are development guarantees by the government or an outside third party.

A development guarantee would credibly commit the issuer to invest a minimum amount of resources in the treated area. Such investment guarantees would imply that $T_{j}^{r}>0$ and, therefore, can help select the neighborhood into an equilibrium that involves coordination among both residents and developers. If the guarantee is not large enough, residential developers and residents would fail to coordinate in the neighborhood and the guarantee ends up being used (in which case the guarantor is nevertheless committed to invest in the neighborhood, a likely undesirable outcome). However, if the guarantee is large enough, so that $T_{j}^{r}$ is at least as large as it would be in the equilibrium with coordination, and fully credible, developers would be willing to build and residents would be willing to live in the neighborhood. In such a case, the guarantee would not end up being used and thus the policy would be ultimately costless. In fact, development guarantees if credible need only be high enough to induce the marginal entrant to build in the neighborhood. Put another way, in real terms, the guarantee needs to be greater than $\left(n_{j}-1\right)\left(V h_{j}^{v}+F_{j}\right)$, where $n_{j}$ and

\footnotetext{
${ }^{14}$ In banking, for instance, the seminal work of Diamond and Dybvig (1983) features both a bank run and a no-run equilibrium that also hinge on a coordination problem among agents, and deposit insurance has been advocated as an effective way to avoid the bank run equilibirum.
} 
$h_{j}$ are the values that obtain in the neighborhood equilibrium with coordination. By determining the value of $T_{j}^{r}$ in the non-degenerate equilibrium (which itself depends on the configuration of the whole city and any guarantees in place in other vacant neighborhoods), our analysis allows us to quantify the magnitude of the required guarantees for the policy to be successful, and the potential set of resources that have to be promised (and could be at risk if something fails).

In the analysis below, we present a series of counterfactuals that consider three approaches: i) we allow all 52 vacant neighborhoods to move into a coordinated equilibrium at the same time, ii) we allow each vacant neighborhood to move into a coordinated equilibrium one at a time, and iii) we allow particular tract groups to move into a coordinated equilibrium in a way that resembles the desired outcome for plans advocated by non-profit and other agencies to improve the city. In particular, for the latter scenarios, we make use of the various proposals that DFC, an organization of planning experts, citizens, and civic leaders, has put forward as perhaps the most well-known strategic vision for the future of Detroit. To our knowledge, our analysis is the first to quantify the potential benefits and effects on allocations of these policies.

\subsection{Computing Counterfactuals}

To compute counterfactual scenarios, where we allow some previously vacant residential tracts to move into a coordinated equilibrium, requires that we first make a few choices. In particular, we need to assign neighborhood-specific parameters to the vacant tracts. Since all tracts contain some business activity, we already have values for productivity, $A_{j}$, and the amount of business land, $\bar{T}_{j}^{b}$. We are then missing $F_{j}, \sigma_{j}$, and $\bar{T}_{j}^{r}$. To determine $F_{j}$, and $\sigma_{j}$ for a given tract $j \in \Omega^{v}$, we adopt the corresponding values in its nearest partially developed census tract, obtained in Section 4. Straight-line distances are used to determine the nearest tract to a given vacant tract. To determine $\bar{T}_{j}^{r}$, we make use of data on total available residential land in the tract under consideration, less business and public land as reported by the city assessor's data.

In addition to assigning values to the local parameters for vacant residential neighborhoods, we need to assign values of $F_{j}$ for all fully developed tracts. Indeed, in computing a counterfactual exercise, we need to account for the possibility that some previously fully-developed tracts might revert to being partially developed as a consequence of the policy.15 Throughout the analysis, we assign the median level of $F_{j}$ to fully developed tracts in the city since, in the suburbs of Detroit where most tracts are fully developed (see Figure 3), the nearest tract can be very far. Observe also that in a counterfactual exercise, partially developed tracts might conceivably become fully developed. Thus, an upper bound $\bar{T}_{j}^{r}$ is needed for those tracts as well, which we obtain in exactly the same way as for the vacant tracts as described in the data appendix.

\footnotetext{
${ }^{15}$ As described in Section 2, between 1910 and 1930, many if not all of the presently vacant tracts in Detroit contained large contiguous neighborhoods composed of single-family structures. In practice, having allowed for this possibility in our quantitative simulations, no fully developed tract reverts to a semi-developed state.
} 


\subsection{The Value of Coordination in One Tract}

In an open city were individuals can move in and out of the city at a given utility level $\bar{u}$, changes to the structure of the city have by construction no effect on the welfare of workers. The gains or losses that result from a change in the organization of the city can, however, be measured by other criteria. One such criterion relates to the corresponding increase or decrease in total residential rents. This change would reflect any additional aggregate residential investment that the city generates following the change in policy, in addition to any change in rents in tracts where developers earn positive profits. Evidently, a change in policy would also affect the number of agents in the city, as well as the rents generated by business land. We can, therefore, also measure its effects based on corresponding changes in population size or changes in total business rents. In fact, given that we postulate the presence of absentee landlords who own commercial land, and that these landlords are the only agents who gain from the policy (recall that workers all get $\bar{u}$, while final goods firms and developers make zero profits, except in fully developed areas for the latter), increases in business land rents constitute a pure economic gain from the policy. Thus, perhaps the clearest way to measure the economic gains resulting from a given policy change is to sum the change in profits earned by residential developers and the change in business rents. Below, we consider different policy proposals according to these three alternative criteria.

Figure 10 presents the increase in total city-wide residential rents as a result of solving the coordination problem in each of the 52 vacant tracts one at a time. The color associated with each tract in the Figure represents the total increase in city-wide rents from a move to the coordinated equilibrium in that tract only. The heterogeneity in the increase in total rents across tracts (and corresponding residential investments) is quite pronounced. The vacant tract which generates the largest increase in citywide rents, were it to be in the equilibrium with coordination, is tract 52, a small tract at the boundary with the city of Hamtramck (which is surrounded by the city of Detroit). With a move to the equilibrium with positive population and residential development, that tract alone generates an increase in citywide residential land rents of about 7.5 million dollars. This result reflects in part the fact that its closest neighboring tract, tract 48 in Hamtramck, is itself a relatively prosperous and dense neighborhood with high residential prices for Detroit. In contrast, other tracts generate less than one tenth of that amount in additional city-wide residential rents. This heterogeneity points to the importance of track selection when implementing "development guarantees". Choosing the correct neighborhoods, and the corresponding required investment guarantees, can change the policy outcomes dramatically.

Figure 11 presents the total city-wide increases in population and business rents resulting from moving each of the 52 vacant tracts to a coordinated equilibrium one at a time. As with residential rents, both maps point to a wide heterogeneity of outcomes from moving a single tract to an equilibrium with residential development and population. Population in the city can increase from less than 80 residents to more than 800, while business rents would rise to between half a million and more than two and a half million. One conclusion that emerges from these figures, however, is that the ranking of tracts in terms of the overall effects of development guarantees, put into effect in each tract individually, is quite similar across all three 


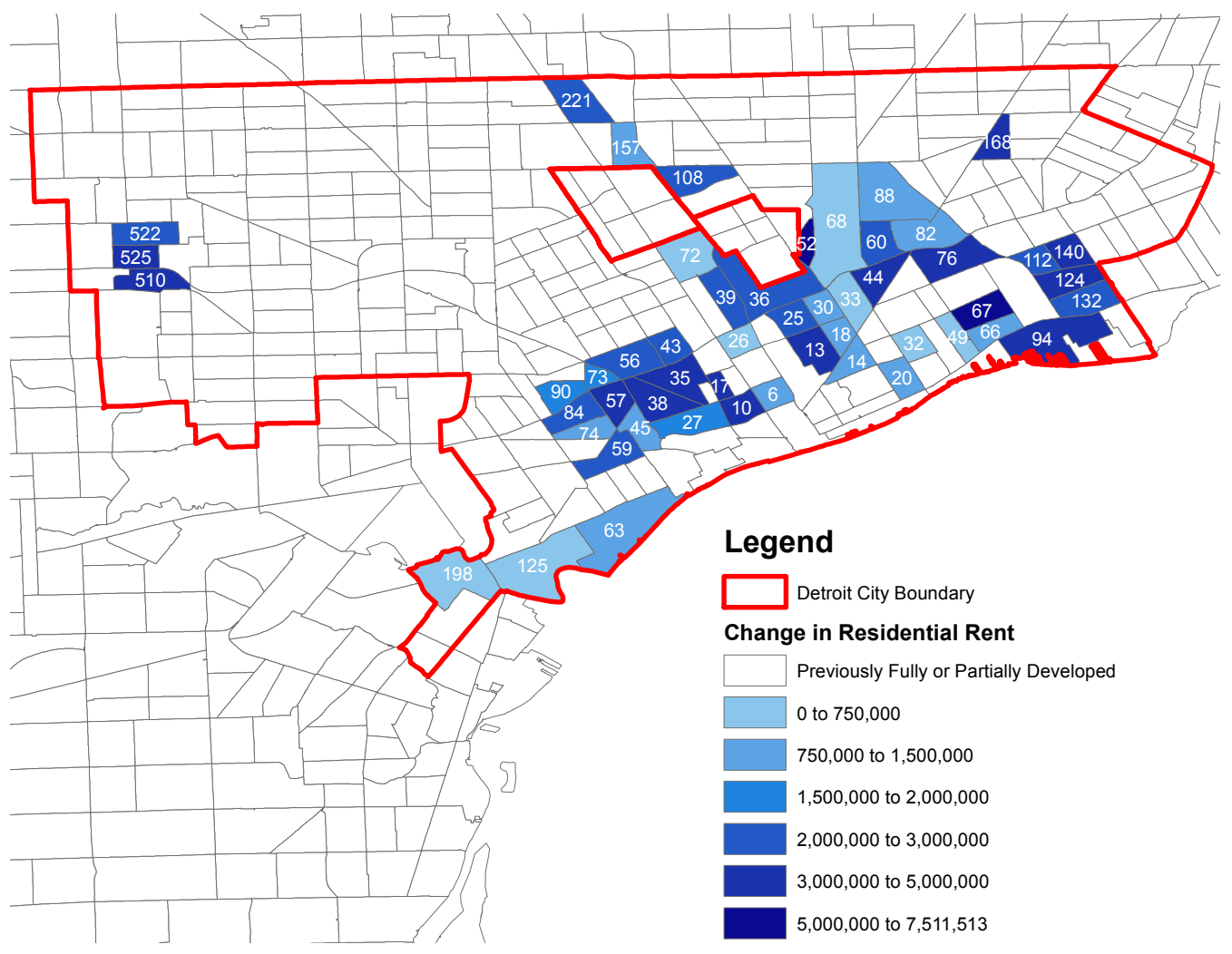

Figure 10: Total Citywide Residential Rent Increase from Coordinating Residential Development in One Tract

measures. The tracts that generate the largest effects on residential rents also tend to generate the largest effects on population and business rents. This finding suggests that policy proposals, all else equal, might more easily achieve some degree of consensus among concerned stakeholders, since different stakeholders might weight these effects in different ways.

\subsection{Detroit Future City}

Detroit Future City is a civic organization created in 2012 with the mission of providing guidance in laying out a vision for the future of Detroit. The Detroit Future City (DFC) Strategic Framework lays out perhaps the best known desired image of what the city of Detroit should look like, 10, 20, and 50 years into the future. This framework points to both the strengths and weaknesses of Detroit's current urban configuration. In highlighting the significant amount of vacancies near the city center that contribute to blight and declining property values, the DFC Strategic Framework in part focuses on key zones for residential development that align with a subset of the vacant census tracts in our study. In particular, DFC proposes several distinct plans for development that emphasize different criteria. In this paper, we focus on residential development 

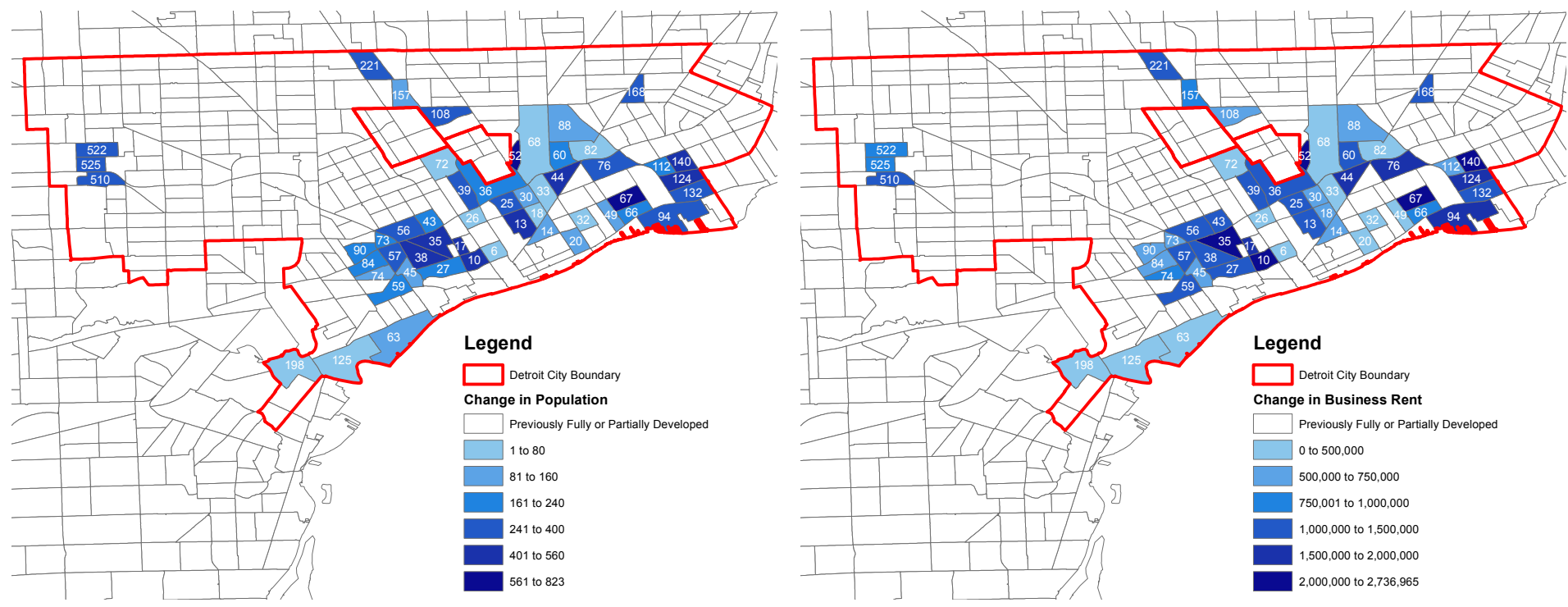

Figure 11: Total Citywide Change in Population and Business Rents from Coordinating Residential Development in One Tract

and quantify the effects of several of the DFC proposals for its vision of Detroit 50 years into the future. The most ambitious proposal, which we refer to the Detroit Future City (DFC) counterfactual, involves 22 tracts. This DFC proposal considers different residential land use typologies. Examples of such typologies include 'green residential', that emphasizes landscape-based neighborhoods, 'traditional low density,' characterized by detached single family houses on large parcels, or 'live plus make,' where housing is located near artisanal and small fabrication facilities or workshops. These various residential land use typologies include different combinations of a smaller number of residential tracts, and are individually evaluated and compared as counterfactuals in the on-line appendix.

We carry out the DFC counterfactual by exploring an equilibrium where the 22 tracts matched to the DFC's strategic framework have switched from a no-development equilibrium to one with positive residential population. We then explore other potential configurations of 22 tracts that can potentially yield larger gains.

The first step in the analysis requires that we identify the tracts in the DFC proposal on a map of Detroit, and compare them with the individual tracts identified in the previous sections as yielding the largest gains with respect to land rents and investment. Figure 12 reproduces Figure 10 but adds an outline of the tracts in the DFC proposal (left). It also shows an outline of an alternative plan where we select the 22 tracts that provide the highest increases in residential rents as each tract switches to an equilibrium with residential population individually (right). We refer to the latter plan as the 'Best 22 Residential' plan. It is evident from the maps that the two proposals overlap only in part, sharing only 11 out of 22 tracts. One of the qualitative differences is that the DFC proposal focuses on developing the areas closest to the downtown 
core, while the Best 22 Residential plan covers some of the same areas but also areas in a wider outer ring.
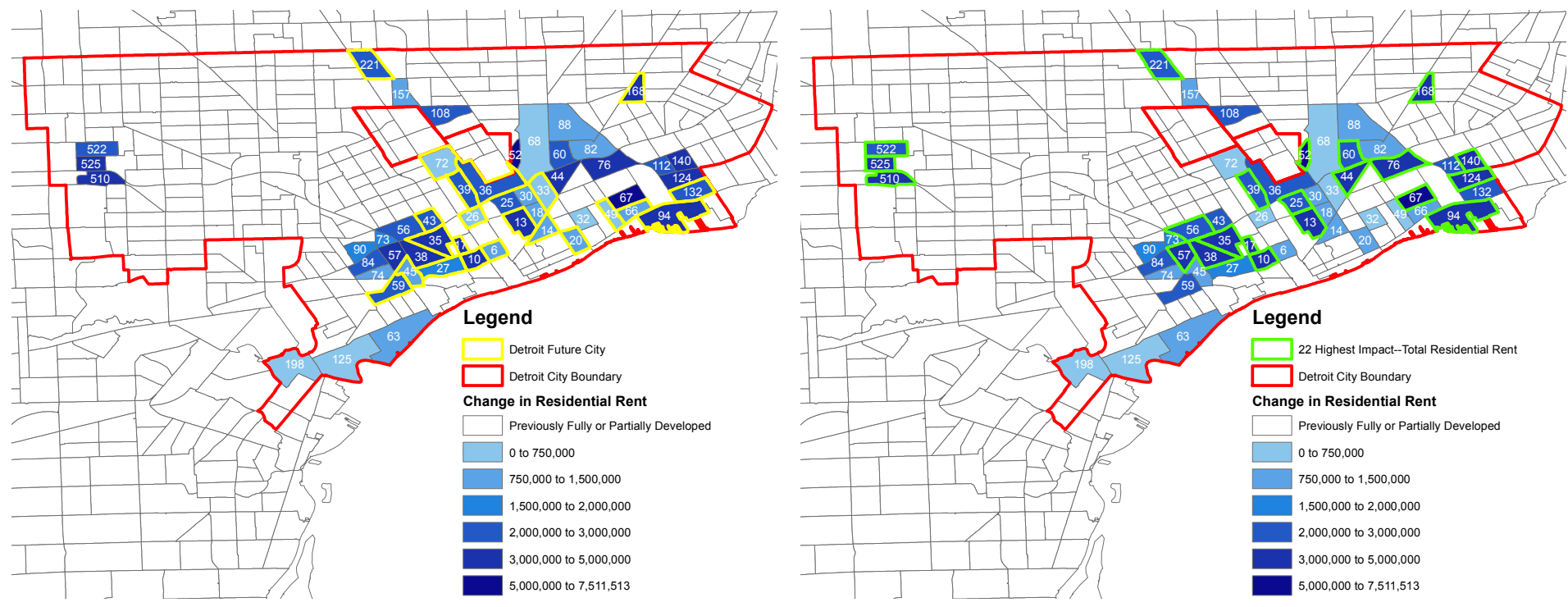

Figure 12: DFC Strategic and Best 22 Residential Plans Compared to Gains in Total Rents from Coordinating Individual Tracts

One might argue that the comparison above is not entirely complete since it does not take into account the complementarities that could result from coordinating several tracts jointly rather than one at a time. Below, we compare the implications of these proposals when the combined effects from coordinating groups of tracts jointly are taken into account. However, it is important to note that the proposal we refer to as the 'Best 22' grouping does not select the best 22 tract combination, out of all possible tract combinations, taking any complementarity effect into account. Rather, we simply rank the citywide effects resulting from moving each tract individually to an equilibrium with coordination as the main criterion, and then choose the 22 tracts with the largest gains. A direct implication is that the true optimal policy might differ slightly from our 'Best 22' calculation. Finding the best combination of tracts, out of all possible combinations of vacant tracks, constitutes a prohibitively large computational task, and we cannot guarantee that such a policy would be identical to our 'Best 22' proposal. ${ }^{16}$ However, given that the effects on residential rents of switching a vacant neighborhood to an equilibrium with positive residential population are fairly local, the difference in tract sets is unlikely to be large. In any case, we more precisely consider the 'Best 22' proposal as a lower bound on what an optimal policy could potentially achieve.

We also carry out similar exercises with alternative criteria to determine the best 22 tracts. In particular, we consider the tracts that yield the largest increases in population or aggregate business rents in a coordinated equilibrium with positive residential development and population. The resulting track selection using these alternative criteria ends up looking quite similar. Using citywide changes in population, 21 tracts end

\footnotetext{
${ }^{16}$ Taking into account all possible 22 tract combinations, out of 52 vacant tracts, amounts to $\frac{52 !}{30 ! \times 22 !}$ counterfactual scenarios.
} 
up being selected in common with those selected according to the largest increases in residential land rents, implying that only one track differs. Using changes in citywide business rents, 18 tracts are common to the selection according to citywide residential land rents, while only four tracks differ. Figure 13 outlines the 22 tracts that, when individually switched to an equilibrium with coordination among residents and developers, yield the largest gains in citywide population and business rents. One notable qualitative difference is that the selection of 'Best 22' tracts based on implied changes in business rents focuses on coordinating only the tracts located in a relatively tight ring across the business area, leaving out those farther away from the central business district.
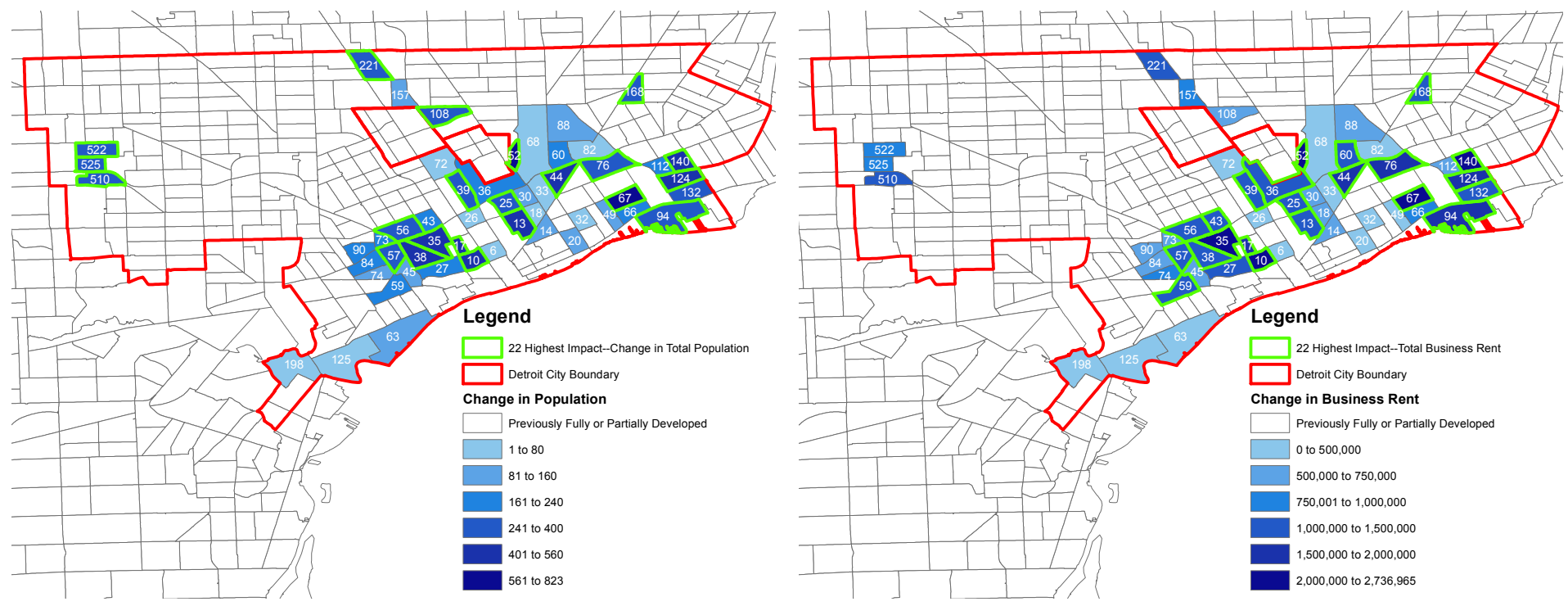

Figure 13: Best 22 Tracts Based on Population and Business Rents

Table 3 presents some citywide statistics corresponding to the alternative policy counterfactuals. The first column in Table 3 presents the outcomes for the benchmark equilibrium, which matches by construction the data used to identify the model parameters in Section 4.2 . The second column presents findings from the policy counterfactual that considers development guarantees for the 22 tracts selected in the DFC strategic plan. The next three columns present findings for alternative 'Best 22' tracts according to citywide business rents, residential rents, and population criteria. The final column presents the outcome of an exercise where all vacant tracts are allowed to switch into an equilibrium with coordination. In these exercises, apart from that in the last column, 22 tracts are always simultaneously allowed to switch from a no-development to a development equilibrium, so that the findings reported in Table 3 reflect any complementarities between those tracks.

In all policy counterfactuals, switching tracks into an equilibrium with coordination increases residential development which attracts more residents to the city. Naturally, the proposal where tracts are selected according to the implied increases in population yields the largest increase in residents among the policies 


\begin{tabular}{lcccccc}
\hline \hline Detroit & Benchmark & DFC & Best 22 Bus. & Best 22 Res. & Best 22. Pop. & All 52 \\
\hline Residents & 126,430 & 131,466 & 134,784 & 135,286 & 135,312 & 139,455 \\
Mean Wages, \$ & 31,996 & 31,922 & 31,869 & 31,875 & 31,875 & 31,801 \\
S.D. Wages, \$ & 10,136 & 10,098 & 10,110 & 10,130 & 10,132 & 10,081 \\
Mean Res. Rents, \$/Sq. Ft. & 1.47 & 1.43 & 1.43 & 1.43 & 1.43 & 1.37 \\
S.D. Res. Rents, \$/Sq. Ft. & 0.05 & 0.05 & 0.05 & 0.05 & 0.05 & 0.05 \\
Total Res. Rents, Mill. \$ & 1,223 & 1,270 & 1,301 & 1,304 & 1,303 & 1,343 \\
Total Bus. Rents, Mill. \$ & 2,181 & 2,205 & 2,217 & 2,216 & 2,215 & 2,235 \\
\hline
\end{tabular}

Table 3: Detroit Proper Outcomes for Alternative Policies

considering 22 tracts. This proposal increases the number of residents in Detroit proper by 8882 residents or about 7 percent. Allowing all 52 tracts to coordinate in the equilibrium with development yields an increase of 10 percent in the number of residents. Given that the supply of new residents to the city is perfectly elastic at $\bar{u}$, none of these scenarios changes residential mean rents per square foot significantly; they decrease slightly within Detroit proper because rents in the newly developed tracts tend to be lower than the existing tract average and the city has relatively few fully developed tracts. Only in the case where we coordinate all 52 tract do residential rents per square foot fall slightly. The influx of workers into the city lowers wages, although the changes are small in all cases.

Table 3 also presents total yearly residential and business rents in millions of dollars. Total residential rents amount to about 1.2 billion dollars while total business rents amount to about 2.2 billion dollars per year. Allowing for a coordination equilibrium in the best 22 tracts according to largest residential rent gains increases residential rents by 81 million dollars per year or 6.6 percent. In contrast the DFC strategic proposal increases rents by 47 million per year or 3.8 percent. Therefore, selecting the 'Best 22' tracts according to where residential investment is largest in a counterfactual yields 72 percent additional investment relative to the DFC proposal.

The findings are somewhat less pronounced when examining business rents. Consider the 'Best 22' plan according to the tracts that generate the largest individual increases in business rents. This policy raises business rents by about 35 million per year or 1.6 percent. The DFC proposal increases business rents by 24 million per year. Therefore, in terms of business rents, the model-selected policy yields an increase in gains of 46 percent relative to the DFC strategic plan. Note that, as mentioned above, all of the 'Best 22' policies in Table 3 yield very similar outcomes given that the set of selected tracts overlap significantly. If all 52 tracts are allowed to switch to an equilibrium with coordination, gains can amount up to 54 million per year or 2.5 percent relative to the benchmark equilibrium.

Table 4 presents the whole set of changes in residential and business rents, as well as changes in population, resulting from these different policy counterfactuals. The table further separates the outcomes into those that are experienced directly in the treated tracts versus those that are experienced in the remaining 
tracts of Detroit proper. Table 4 also shows the effect of these policies for the whole sample of tracts in greater Detroit, which includes the counties of Wayne, Macomb, and Oakland. Finally, the first row of the table gives the required development guarantee needed to induce a switch to the equilibrium with coordination, calculated as $\sum_{\Omega^{p}}\left(F j+V h_{j}^{\nu}\right)\left(n_{j}-1\right)$, where $\Omega^{p}$ corresponds to the set of tracts in which the policies are implemented.

\begin{tabular}{lccccc}
\hline \hline & DFC & Best 22 Bus. & Best 22 Res. & Best 22. Pop. & All 52 \\
\hline Dev. Guarantee, Mill. \$ & 41.156 & 70.581 & 73.440 & 73.001 & 106.281 \\
Detroit Proper: & & & & & \\
$\Delta$ in Res. Rent, Mill. \$ & & & & & \\
$\quad$ Total & 47.452 & 77.829 & 80.758 & 80.502 & 120.347 \\
$\quad$ Treated Tracts & 45.797 & 75.159 & 77.443 & 77.064 & 115.894 \\
$\quad$ Other Tracts & 1.656 & 2.670 & 3.315 & 3.438 & 4.453 \\
$\Delta$ in Bis. Rent, Mill. \$ & & & & & \\
$\quad$ Total & 23.502 & 35.922 & 34.525 & 33.792 & 54.254 \\
$\quad$ Treated Tracts & 9.857 & 8.657 & 4.469 & 4.505 & 22.370 \\
$\quad$ Other Tracts & 13.645 & 27.265 & 30.056 & 29.287 & 31.884 \\
$\Delta$ in Population & & & & & \\
$\quad$ Total & 5,036 & 8,354 & 8,856 & 8,882 & 13,025 \\
$\quad$ Treated Tracts & 4,746 & 7,893 & 8,347 & 8,369 & 12,296 \\
$\quad$ Other Tracts & 290 & 461 & 510 & 514 & 730 \\
Greater Detroit: & & & & & \\
$\Delta$ in Res. Rent, Mill. \$ & 58.676 & 96.350 & 102.751 & 103.142 & 150.847 \\
$\Delta$ in Bis. Rent, Mill. \$ & 61.112 & 100.356 & 107.024 & 107.431 & 157.124 \\
$\Delta$ in Population & 7,043 & 11,663 & 12,540 & 12,617 & 18,301 \\
\hline
\end{tabular}

Table 4: Development Guarantees and Policy Outcomes in Detroit Proper and Greater Detroit

Table 4 underscores some key implications shared by all of the policy proposals. First, in all cases, the plans are worth pursuing; that is all plans yield increases in aggregate residential and business rents combined that exceed the needed development guarantees. Therefore, even if the development guarantees were implemented in a way that ultimately required the guarantors to develop the targeted areas themselves, the policies result in a gain for the city, particularly given the implied increase in business rents (the gains in residential rents in non-treated tracts are generally small). It is important to keep in mind that the hope is for the development guarantees not to be used in equilibrium since, if fully credible, they would be provided only to coordinate private investors and residents. Table 4 shows that the benefits from this policy, once we sum all of their implications for greater Detroit, can be quite large. Second, most of the gains in residential land rents accrue to the treated tracts while most of the gains in business land rents accrue outside of the treated tracts. In fact, about two thirds of increases in business land rents emerge outside of Detroit proper, where all of the treated tracts are located. In contrast, only about a fifth of the increases in residential land 
rents appear outside of the Detroit proper area. Increases in commercial land rents stem primarily from commuting links and general equilibrium effects, because wages change everywhere in the broader city, so that these findings highlight the perils of using partial equilibrium logic to carry out this type of policy assessment. Third, increases in population are quite concentrated in treated tracts, which imply that the newly developed areas provide workers not only to downtown firms but also to the suburbs. In that sense, the policy revitalizes the core of the city as a residential center.

Comparing the different policies presented in the columns of Table 4 again emphasizes that the particular criterion according to which 'Best 22' policy is selected is somewhat immaterial. Out of the set of policies that move 22 tracts into an equilibrium with residential development, the best policy for Detroit as a whole is one where tract selection is guided by the largest effects on population. Making Detroit proper an attractive place to live with enough residential amenities is the key objective of the policy. The DFC strategic proposal emerges as least effective in generating increases in rents, of either type, or population. Specifically, the 'Best 22' plans we consider all generate about 40 percent larger increases along all three dimensions. That said, the needed development guarantees would then also have to be larger.

Net gains to the greater Detroit area become much larger when treating all 52 vacant tracts, which then emerges as the best option. This more ambitious policy generates 157 million dollars a year in additional business rents, and 150 million dollars a year in additional residential land rents. The corresponding development guarantees that would be required totals 106 million dollars. The rate of return for greater Detroit on such a policy, even if one takes the guarantees in their entirety as a pure resource cost (and one should not), is substantial: at least a 50 percent return on investment with an extra 18,301 residents. Put another way, the returns to a well designed policy are potentially quite large. Observe also that the 'Best 22' plans capture about two thirds of these gains while coordinating fewer than half of the tracts. As a consequence, to the degree that development guarantees might conservatively be available only for a more limited set of policies, then targeting the treated tracts judiciously is of the essence. In particular, not all of DFC's strategic framework focuses on residential development and, in fact, suggests developing ecological zones in some of the currently vacant tracts, in particular those surrounding downtown. Our study makes clear that this strategy, while undoubtedly carrying non-pecuniary benefits, also entails a substantial cost.

\subsection{In Detail: Coordination in all 52 Tracts}

The aggregate city statistics presented above do not illustrate, by design, the heterogenous responses of particular neighborhoods to the different policies considered in the analysis thus far. In this section, we make use of the plan that treats all 52 vacant neighborhoods to illustrate and discuss some of these effects across tracts.

In Figure 14, we present the fraction of residential land that is developed in each tract after the policy is implemented ${ }^{17}$ The figure shows that, even after implementation, most of Detroit proper is still only partially developed, that is $T_{j}^{r}<\bar{T}_{j}^{r}$. In many of the areas now in a new equilibrium with coordination,

\footnotetext{
${ }^{17}$ Tracts marked in black represent tracts for which data is not available or includes obvious errors.
} 
residential development uses less than 15 percent of the potentially available residential land. In no sense, therefore, does this policy lead to a booming residential area that becomes congested. Only in a few of the new tracts with residential development does residential land usage exceed 50 percent of the available land, and none of these tracts become fully developed.
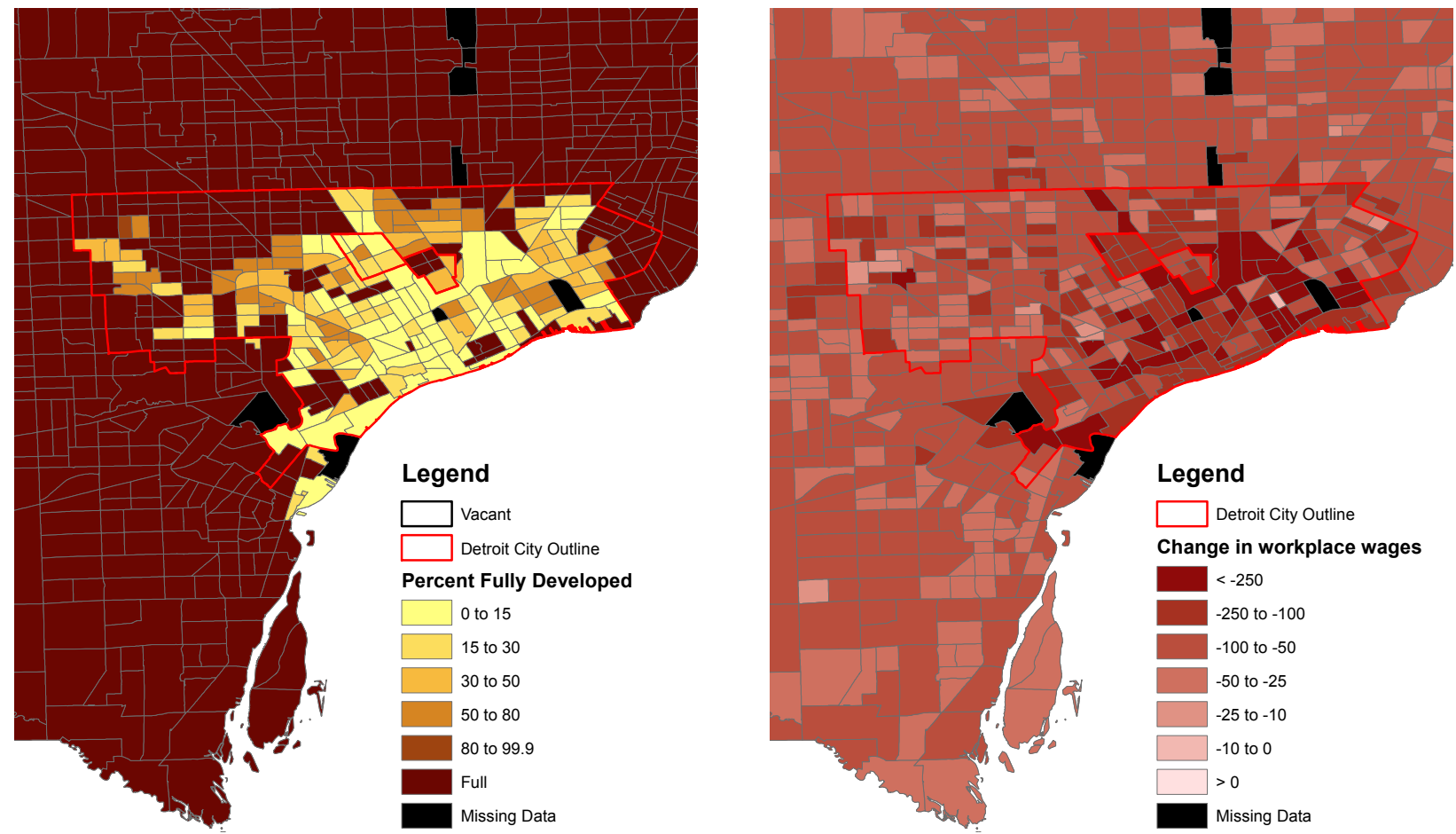

Figure 14: Coordinating All 52 Vacant Tracts, Percent of Developed Residential Land and Change in Workplace Wages

Figure 14 also illustrates the change in workplace wages in each tract. Virtually all tracts experience declines in workplace wages. As agents migrate to the city following a policy aimed at revitalizing Detroit, labor supply naturally increases which tends to depress wages. We discussed this effect earlier in the context of the description of the model and its main mechanisms. As expected, the fall in wages is somewhat more pronounced close to the affected areas, but the general decline in wages is fairly uniform across the city. This general equilibrium effect, which extends well outside Detroit proper, is primarily responsible for the increase in business land rents, through equation (5), described in the previous section.

Figure 15 shows the resulting change in the number of workers and residents at the census tract level. Clearly, a development-guarantee policy that is provided in each of the 52 vacant tracts raises the number of residents in essentially all tracts, although increases are naturally larger in the treated neighborhoods. The areas immediately surrounding the treated tracts sees the smallest gains in residents, while gains in the suburbs are more substantial. This localized pattern makes sense. The newly developed residential areas now house downtown workers who substitute away from housing in other areas of Detroit proper. The change 
in workers and their locations also show some clear patterns. Employment in downtown Detroit increases substantially, but so does employment in many of the suburbs, including Dearborn. The newly developed residential tracts increase labor supply nearby, which depresses wages and encourages firms to employ more workers. Furthermore, workers are not worse off since they enjoy additional residential amenities and the shorter commutes to work.
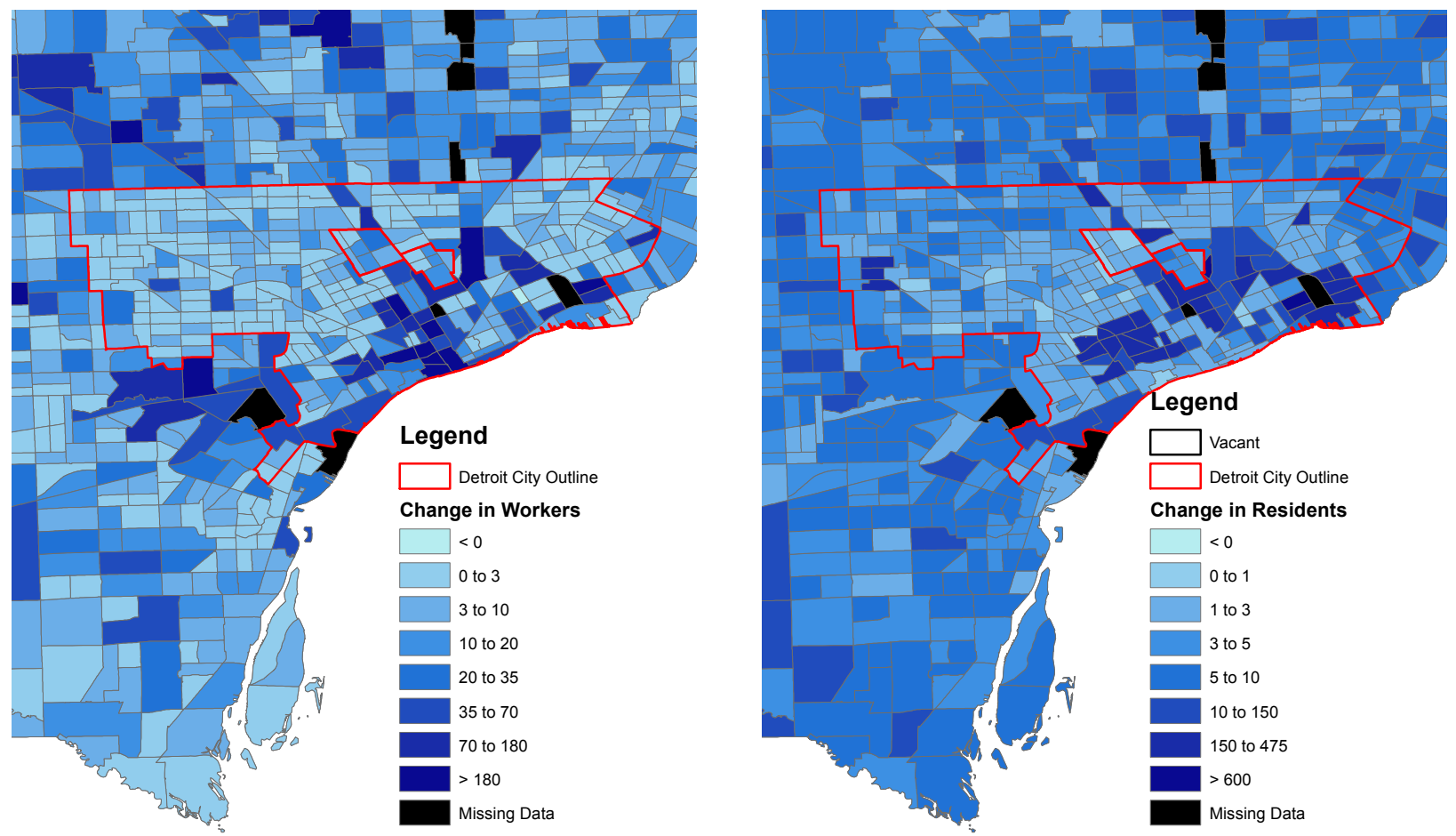

Figure 15: Coordinating All 52 Vacant Tracts, Change in Workers and Residents

The final maps, presented in Figure 16, show the changes in business and residential rents by tract. The results follow closely those discussed in Figure 15. Tracts that gain the most workers are those where business rents increase most, and tracts that gain the most residents are those where residential rents increase most. These findings are natural given our specification of technology and preferences with Cobb-Douglas functions that feature constant factor and consumption shares respectively. Perhaps more interesting in this case are the heterogeneity in the magnitudes of the implied changes. While some of the tracts in downtown Detroit, Dearborn, and other suburbs, can see increases of more than a million dollars in yearly business rents, other tracts near the boarder of Detroit see business rents increase by less than 25,000 dollars. Most tracts experience modest increases in residential land rents, between 15,000 and 60,000 dollars. Only the residential tracts that have switched from being vacant to an equilibrium with residential development show increases in residential rents of more than one hundred thousand dollars. Areas where rents tend to increase the least, either business or residential, are located in the outer ring of the city close to the boundary of 
Detroit proper.
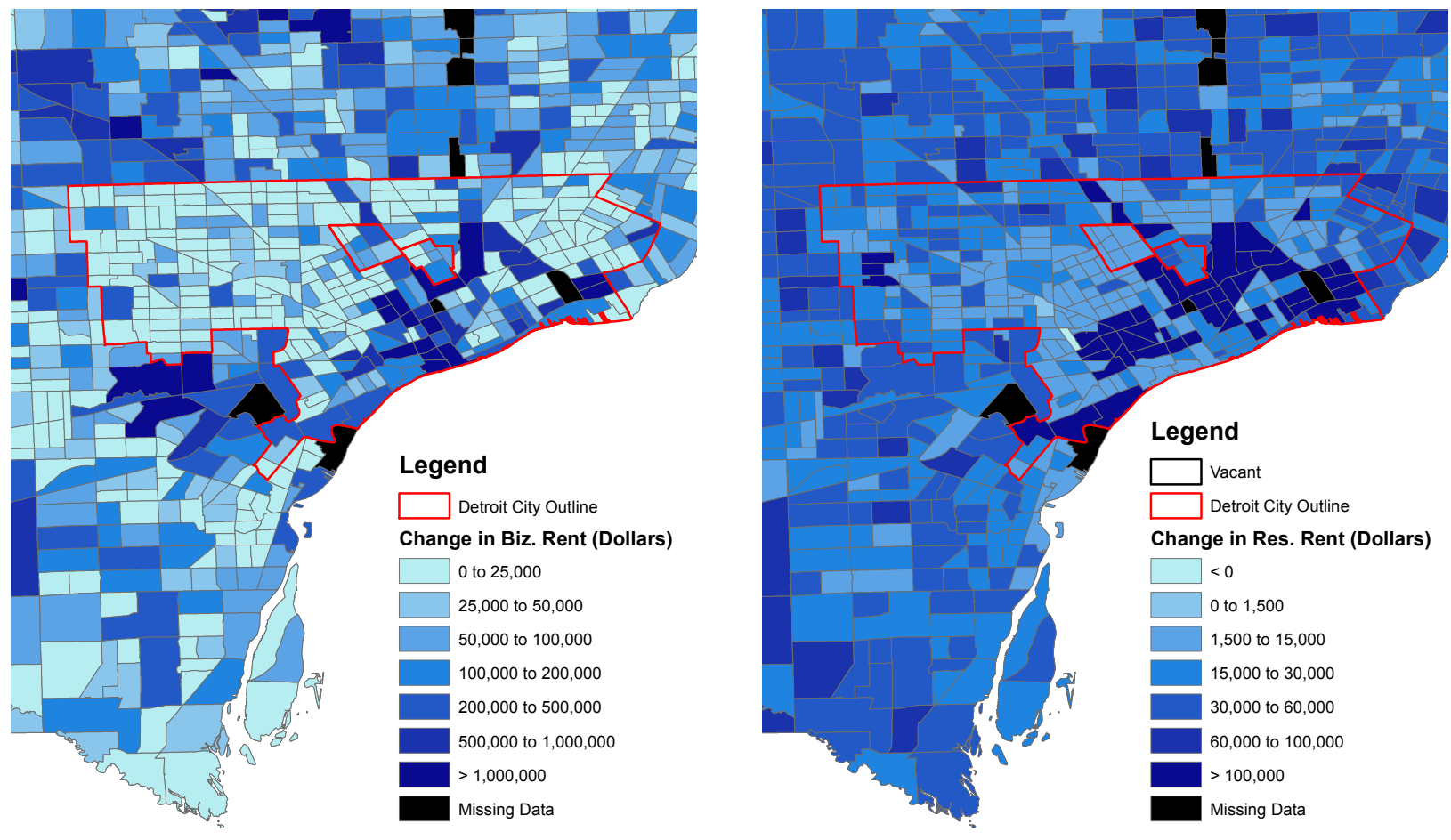

Figure 16: Coordinating All 52 Vacant Tracts, Change in Workers and Residents

\section{Conclusion}

Declining cities have become and likely will continue be a pervasive phenomenon. The fact that cities tend to specialize in certain industries, and that the importance of particular industries and the characteristics of factors they employ vary over time, make this inevitable. Learning how to cope with urban downturns can lead to improved utilization of past investments, and less dissatisfaction by local residents with respect to technological progress and globalization. Cities or regions specialized in declining industries should be able to reinvent themselves to host new thriving industries, albeit perhaps on a smaller scale. So far, this process of urban reinvention has failed.

In this paper, we have argued that inefficiencies associated with urban decline can be related to specific areas of a city, that potentially retain sound underlying fundamentals, but are nevertheless trapped in local neighborhood equilibria in which developers and residents are unable to coordinate their actions. No resident wants to be first to move into, and no developer wants to be first to invest in, a vacant neighborhood. In the case of Detroit, we identified 52 census tracts that can be mapped into such an equilibrium. These tracts were originally developed before the 1930's to accommodate a rapidly growing demand for workers in 
the automobile industry. However, as employment fell in that industry, and some plants moved elsewhere, residential demand and income collapsed leading to riots in 1967 that eventually drove them into a nodevelopment equilibrium. The end result is a distorted, impractical, and inefficient city.

It is no surprise that thriving industries do not necessarily wish to locate in such a city. The high-skilled workers required by the high-tech industry would likely not want to start their lives in vacant neighborhoods near Detroit's downtown, even if such locations are cheap relative to the available urban infrastructure. The necessary density is simply not there, so new workers and firms do not enter.

Our analysis quantifies the forces that sustain this outcome as an equilibrium of the city, and uses the resulting quantitative framework to assess policies that can help vacant neighborhoods switch back to an equilibrium where developers and residents coordinate into building and living in these neighborhoods. In particular, we consider development guarantees, provided by the government or outside parties, that commit to a minimum amount of investment in a targeted vacant area. If fully credible, these guarantees would resolve the coordination problem among private developers and residents, leading to a new equilibrium with positive numbers of active developers and residents. Our framework allows us to quantify the magnitude of the required guarantees in each vacant tract, and to identify the tracts in which the policy would be most effective. In addition, we are able to compare our findings with those of alternative plans that have been advocated by experts and local residents, such as those laid out by the Detroit Future City strategic framework, and to quantify their implications. In all cases, we find that these guarantees can be quite effective. Policies that utilize guarantees in the 22 tracts yielding the largest gains from a switch to an equilibrium with development generate increases in residential and business rents in the hundreds of millions of dollars a year. These can also attract thousands of new residents to the city.

We estimate that a large fraction of the gains stemming from any policy that develops the currently vacant residential areas would accrue to business rents outside Detroit's city boundary by way of general equilibrium effects. Therefore, incorporating the appropriate stakeholders in policy design and initial investments appears to be important. In particular, our analysis underscores the existence and magnitude of mutual gains to different parties, including developers, landowners, and new residents.

In any quantitative analysis, one inevitably confronts the need to abstract from some aspects of reality that might be pertinent. One such dimension is the presence of citywide or region-wide agglomeration effects. In our analysis, we consider local agglomeration effects in production and amenities that are at the heart of the coordination problem we study, but these effects operate only within and not across census tracts. To the degree that agglomeration effects across tracts also matter quantitatively, adding this feature to our analysis would only serve to increase the gains from the advocated policies. In such a case, the gains we measure then become a conservative lower bound. 


\section{References}

[1] Abowd, J. M., B. E. Stephens, L. Vilhuber, F. Andersson, K. L. McKinney, M. Roemer, and S. Woodcock, (2005), "The LEHD Infrastructure Files and the Creation of the Quarterly Workforce Indicators," Technical Paper No. TP-2006-01, U.S. Census, http://lehd.ces.census.gov/doc/technical_paper/tp2006-01.pdf

[2] Ahlfeldt, G., S. Redding, D. Sturm, N. Wolf, (2015), "The Economics of Density: Evidence from the Berlin Wall, Econometrica, vol. 83(6), pp. 2127-2189.

[3] Ahlfeldt, G. and D. McMillen, (2015), "The Vertical City: The Price of Land and the Height of Buildings in Chicago 1870-2010," SERC Discussion paper 180.

[4] Bing, D., (2010), "Mayor Dave Bing Gives the State of the City Address (full transcript)," NEWSTALKWBHC, https://wchbnewsdetroit.newsone.com/246091/mayor-dave-bing-givesstate-of-the-city-address-full-text/.

[5] Bogue, D., (2000), Census Tract Data, 1950: Elizabeth Mullen Bogue File. ICPSR02931v1. Ann Arbor, MI: Inter-university Consortium for Political and Social Research [distributor], http://doi.org/10.3886/ICPSR02931.v1.

[6] Ciccone, A. and R. E. Hall, (1996), "Productivity and the Density of Economic Activity," American Economic Review, vol. 86, pp. 54-70.

[7] Couture, V., and J. Handbury. (2016), "Urban Revival in America, 2000 to 2010," Wharton Working Paper.

[8] Davis, M. and F. Ortalo-Magné, (2011), "Household Expenditures, Wages, Rents," Review of Economic Dynamics, vol. 14(2), pp. 248-261.

[9] Detroit Blight Removal Task Force, (2014), "Detroit Blight Removal Task Force Plan," Retrieved on August 8, 2016, from http://report.timetoendblight.org/.

[10] Detroit Future City Implementation Office, (2012), Detroit Future City: Detroit Strategic Framework Plan. Retrieved on November 23, 2016, from http://detroitfuturecity.com/framework/.

[11] Diamond, D. W., and P. H. Dybvig, (1983), "Bank Runs, Deposit Insurance, and Liquidity," Journal of Political Economy vol. 91(3), pp. 401-419.

[12] Glaeser, E. and J. Gyourko, (2005), "Urban Decline and Durable Housing," Journal of Political Economy, vol. 113(2), pp. 345-375.

[13] Minnesota Population Center and Ancestry.com, (2013), IPUMS Restricted Complete Count Data: Version 1.0 [Machine-readable database]. Minneapolis: University of Minnesota. 
[14] Head, K., and J. Ries, (2001), "Increasing Returns versus National Product Differentiation as an Explanation for the Pattern of US-Canada Trade," American Economic Review, pp. 858-876.

[15] Monte, F., S. Redding, and E. Rossi-Hansberg, (2016), "Commuting, Migration, and Local Employment Elasticities," working paper Princeton University.

[16] Redding, S. and E. Rossi-Hansberg, (2016), "Quantitative Spatial Economics," forthcoming in Annual Review of Economics.

[17] Rossi-Hansberg, E., P.-D. Sarte and R. Owens, (2010), "Housing Externalities," Journal of Political Economy, vol. 118(3), pp. 409-432.

[18] Scorsone, E., (2013), "Depopulation Cities and Chronic Fiscal Stress: The Detroit Story," The Journal of Law and Society, vol. 14, pp. 207-234.

[19] Sugrue, T., (1996), "The Origins of the Urban Crisis: Race and Inequality in Postwar Detroit," Princeton University Press.

[20] Sugrue, T., (2007), "Motor City: The Story of Detroit," History Now 11, www.historynow.org.

[21] Sugrue, T., (2015), "From Motor City to Motor Metropolis: How the Automobile Industry Reshaped Urban America," Automobile in American Life and Society (Dearborn: Henry Ford Museum and University of Michigan 2005), http://www.autolife.umd.umich.edu. 


\section{Appendix A: Solving the Model}

\section{The Basic Set of Equations and Unknowns}

We solve the model given a set of parameters, $\mathcal{P}$, and any set of vacant tracts, $\Omega^{v}=\Omega \backslash\left(\Omega^{F} \cup \Omega^{S}\right)$, as follows:

From equation (11), we have

$$
\pi_{i j}=\frac{\lambda_{i j}\left(w_{i} / \kappa_{i j}\right)^{\theta}}{\sum_{i=1}^{J} \lambda_{i j}\left(w_{i} / \kappa_{i j}\right)^{\theta}} .
$$

Then, from equation $(23)$, we have

$$
T_{j}^{r}=\left\{\begin{array}{cc}
\bar{T}_{j}^{r}, & \text { if } j \in \Omega^{F} \\
\frac{(1-\gamma) R_{j} \sum_{j=1}^{J} \pi_{i j} w_{i}}{q_{j}^{r}}, & \text { if } j \in \Omega^{S}
\end{array},\right.
$$

and from equation (17), in equilibrium,

$$
R_{j}=\left(\frac{\bar{u}(1-\gamma)^{1-\gamma}\left\{\sum_{i=1}^{J} \pi_{i j} w_{i}\right\}^{1-\gamma}}{\Gamma\left(\frac{\theta-1}{\theta}\right)\left(T_{j}^{r}\right)^{1-\gamma}\left[\sum_{i=1}^{J} \lambda_{i j}\left(w_{i} / \kappa_{i j}\right)^{\theta}\right]^{\frac{1}{\theta}}}\right)^{\frac{1}{\sigma_{j}+\gamma-1}} .
$$

Residential prices are given by

$$
q_{j}^{r}=\left\{\begin{array}{cl}
(1-\gamma) \frac{R_{j}}{\bar{T}_{j}^{r}} \sum_{i=1}^{J} \pi_{i j} w_{i} & \text { if } j \in \Omega^{F} \\
\left(\frac{F_{j}}{(v-1) V}\right)^{\frac{v-1}{v}} v V & \text { if } j \in \Omega^{S}
\end{array} .\right.
$$

Finally from equation (24), reproduced below, wages solve

$$
\left(\frac{A_{i} \beta}{w_{i}}\right)^{\frac{1}{1-\beta-\alpha}} T_{i}^{b}=\sum_{j=1}^{\underline{J}} \pi_{i j} R_{j} .
$$

In general, equations 26 through 30 make up a system of $J^{2}+4 J$ equations in the same number of unknowns, given by $\pi_{i j}(\mathcal{P}), T_{j}^{r}(\mathcal{P}), R_{j}(\mathcal{P}), q_{j}^{r}(\mathcal{P})$ and $w_{i}(\mathcal{P})$, where $J=1151$ census tracts in our application.

In solving this system, we must be cognizant that the sets of fully developed locations, $\Omega^{F}$, and partially developed locations, $\Omega^{S}$, are themselves endogenous and determined as part of the equilibrium. Specifically, given that

$$
T_{j}^{r}\left(R_{j}, w_{j}, \pi_{i j}, q_{j}^{r} ; \mathcal{P}\right)=\frac{(1-\gamma) R_{j} \sum_{i=1}^{J} \pi_{i j} w_{i}}{q_{j}^{r}},
$$

in the lower portion of equation 27 represents an unconstrained level of development for census tract $j$, it 
must be the case that

$$
j \in\left\{\begin{array}{ll}
\Omega^{F} & \text { if } T_{j}^{r}\left(R_{j}, w_{j}, \pi_{i j}, q_{j}^{r} ; \mathcal{P}\right) \geq \bar{T}_{j}^{r} \\
\Omega^{S} & \text { if } T_{j}^{r}\left(R_{j}, w_{j}, \pi_{i j}, q_{j}^{r} ; \mathcal{P}\right)<\bar{T}_{j}^{r}
\end{array} .\right.
$$

A direct implication is that the sets of fully developed and semi-developed locations, $\Omega^{F}$ and $\Omega^{S}$, potentially change in counterfactual scenarios relative to a given benchmark. All other equilibrium allocations follow in a straightforward manner given the vector of equilibrium wages, $w_{j}$.

\section{Solution Algorithm}

This section describes the algorithm used to implement the model solution described above.

1. Guess a vector of wages, $\mathbf{w}^{0}=\left(w_{1}^{0}, \ldots, w_{J}^{0}\right)^{\prime}$.

2. Given this guess, calculate the matrix of commuting patterns,

$$
\pi_{i j}\left(w_{i}=w_{i}^{0}\right)=\frac{\lambda_{i j}\left(w_{i} / \kappa_{i j}\right)^{\theta}}{\sum_{i=1}^{J} \lambda_{i j}\left(w_{i} / \kappa_{i j}\right)^{\theta}} .
$$

3. Given our guess $\mathbf{w}^{0}$ and $\pi_{i j}\left(w_{i}=w_{i}^{0}\right)$ from step 2, from equation 23 in the text, we compute

$$
T_{j}^{r}\left(w_{i}=w_{i}^{0}\right)=\left(\frac{\bar{u}(1-\gamma)^{1-\gamma}\left[\left(\frac{(v-1) V}{F_{j}}\right)^{\frac{v-1}{v}}\left(\frac{1-\gamma}{v V}\right)\right]^{\sigma_{j}+\gamma-1}}{\Gamma\left(\frac{\theta-1}{\theta}\right)\left\{\sum_{i=1}^{J} \lambda_{i j}\left[w_{i} / \kappa_{i j}\right]^{\theta}\right\}^{\frac{1}{\theta}}}\right)^{\frac{1}{\sigma_{j}}} \sum_{i=1}^{J} \pi_{i j}\left(w_{i}=w_{i}^{0}\right) w_{i},
$$

which also corresponds to the lower portion of equation (27).

(a) Ensure that $T_{j}^{r}\left(w_{i}=w_{i}^{0}\right)$ above satisfies its upper bound constraint,

$$
T_{j}^{r}\left(w_{i}=w_{i}^{0}\right)=\left\{\begin{array}{cc}
\bar{T}_{j}^{r} & \text { if } T_{j}^{r}\left(w_{i}=w_{i}^{0}\right) \geq \bar{T}_{j}^{r} \\
T_{j}^{r}\left(w_{i}=w_{i}^{0}\right) & \text { otherwise }
\end{array}\right.
$$

4. At $\mathbf{w}^{0}$, and given $\pi_{i j}\left(w_{i}=w_{i}^{0}\right)$ and $T_{j}^{r}\left(w_{i}=w_{i}^{0}\right)$ from steps 2 and 3 respectively, compute residential population,

$$
R_{j}\left(w_{i}=w_{i}^{0}\right)=\left(\frac{\bar{u}(1-\gamma)^{1-\gamma}\left\{\sum_{i=1}^{J} \pi_{i j}\left(w_{i}=w_{i}^{0}\right) w_{i}\right\}^{1-\gamma}}{\Gamma\left(\frac{\theta-1}{\theta}\right)\left(T_{j}^{r}\left(w_{i}=w_{i}^{0}\right)\right)^{1-\gamma}\left[\sum_{i=1}^{J} \lambda_{i j}\left(w_{i} / \kappa_{i j}\right)^{\theta}\right]^{\frac{1}{\theta}}}\right)^{\frac{1}{\sigma_{j}+\gamma-1}} .
$$


5. At $\mathbf{w}^{0}$ and in each census tract, compute labor supply,

$$
\sum_{j=1}^{\underline{J}} \pi_{i j}\left(w_{i}=w_{i}^{0}\right) R_{j}\left(w_{i}=w_{i}^{0}\right)
$$

and labor demand,

$$
L_{i}\left(w_{i}=w_{i}^{0}\right)=\left(\frac{A_{i} \beta}{w_{i}}\right)^{\frac{1}{1-\beta-\alpha}} T_{i}^{b}
$$

6. Compute excess labor demand at $\mathbf{w}^{0}, X_{i}\left(w_{i}=w_{i}^{0}\right)$, in each census tract,

$$
X_{i}\left(w_{i}=w_{i}^{0}\right)=\left\{L_{i}\left(w_{i}=w_{i}^{0}\right)-\sum_{j=1}^{\underline{J}} \pi_{i j}\left(w_{i}=w_{i}^{0}\right) R_{j}\left(w_{i}=w_{i}^{0}\right)\right\} .
$$

7. At our initial guess, $\mathbf{w}^{0}$, any given census tract may have an excess supply of or demand for labor, $X_{i}\left(w_{i}=w_{i}^{0}\right) \lessgtr 0$. Then, if $\sum_{i=1}^{J}\left|X_{i}\left(w_{i}=w_{i}^{0}\right)\right| \geq \varepsilon$ for some small $\varepsilon$, we update wages in each census tract according the state of its labor market. In particular, our new guess, $\mathbf{w}^{1}$, satisfies

$$
\mathbf{w}^{1}=\mathbf{w}^{0}+\delta \mathbf{X}
$$

for some small positive $\delta$ where $\mathbf{X}=\left(X_{1}, \ldots, X_{J}\right)^{\prime}$.

8. Iterate on steps 1 through 7 until $\sum_{i=1}^{J}\left|X_{i}\left(w_{i}=w_{i}^{0}\right)\right|<\varepsilon$. 